\title{
Distribution Fees and Mutual Fund Flows: Evidence from a Natural Experiment in the Indian Mutual Funds Market*
}

\author{
Santosh Anagol ${ }^{1}$, Vijaya Marisetty ${ }^{2}$, Renuka Sane $^{3}$, and Buvaneshwaran Venugopal ${ }^{4}$ \\ ${ }^{1}$ Wharton \\ ${ }^{2}$ Royal Melbourne Institute of Technology \\ ${ }^{3}$ Finance Research Group, Indira Gandhi Institute for Development Research \\ ${ }^{4}$ University of Houston
}

December 31, 2012

\begin{abstract}
Mutual fund companies typically charge investors distribution fees, such as $12 \mathrm{~b}-1$ fees in the United States, which they then use to pay commissions to brokers. We evaluate a major Indian investor protection reform that limited the ability of mutual funds to charge distribution fees to pay broker commissions. We identify the impact of this policy change by comparing funds charging high distribution fees prior to the reform to those charging low distribution fees; we show that trends in asset growth across these groups prior to the reform were similar, and argue that a comparison of their asset growth after the reform is indicative of the policy impact. Contrary to claims by industry that banning distribution fees would dramatically reduce investment in mutual funds, we find no evidence that the post-reform asset growth was lower for funds charging higher distribution fees prior to the reform. We primarily find that asset growth in funds with previously high distribution fees was higher after the policy change. At the aggregate level, our results suggest that Indian mutual fund growth in the post-policy period was lower for reasons independent of this policy change, such as a general move away from mutual funds towards real assets such as gold and real estate following the 2008 financial crisis.
\end{abstract}

*PRELIMINARY AND INCOMPLETE, PLEASE DO NOT CIRCULATE. We thank Shawn Cole, Ruchi Chojer, Mark Duggan, Fernando Ferreira, G. Sethu, Saikat Deb, Sayee Srinivasan, K. N. Vaidyanathan, Shing-Yi Wang and participants at Wharton and the IGIDR Emerging Markets Finance Conference for valuable feedback. We thank ACE Fintech Pvt Ltd for providing access to the Indian mutual funds data, and Karvy Computershare Limited for access to disaggregated data on mutual fund flows. We thank the Center for the Advanced Study of India at the University of Pennsylvania for funding. Maria Guo, Mengshu Shen, and Jason Tian provided excellent research assistance. This paper was earlier circulated as: "Are Mutual Funds Sold or Bought? Evidence from the Indian Mutual Funds Market". 


\section{Introduction}

The financial crisis of 2008 spurred an active policy debate on the optimal way to pursue consumer financial protection (Campbell et al., 2011). Two main policy options have received attention (Ko and Lee, 2011). One approach is to empower consumers to make better financial decisions through financial literacy training and disclosure regulation. A small but growing literature evaluates financial literacy training programs, with mixed results. ${ }^{1}$

Another policy approach is direct intervention into how financial products are sold, such as capping or banning commissions to financial product brokers. A number of significant reforms have already been made. The U.K. Financial Services Authority announced in June 2009 that, starting in 2012, there would be a ban on commissions paid to independent financial advisors by financial product providers. Australia will implement a similar ban on commissions in July 2013 (Bowen, 2011). The scope of these bans on commissions is large, encompassing savings products such as mutual funds as well as insurance and pension products. There is also a longstanding policy debate in the United States on whether mutual funds should be allowed to charge a separate class of operating expenses, known as 12b-1 fees, specifically for the purpose of paying distribution expenses such as broker commissions (Ferris and Chance (1987), Walsh (2005)). ${ }^{2}$

Commissions bans are motivated by the idea that commissions influence brokers to sell products that are not necessarily in line with the interest of their customers (Anagol et al. (2012), Mullainathan et al. (2012)). Policymakers hope that by eliminating commissions, investors will be more likely to directly pay for financial advice, and become more aware about how brokers are compensated. On the other hand, brokers and financial product companies argue that commissions bans reduce the incentive for brokers to educate consumers about financial products. Despite the fact that major reforms have already been undertaken, we have little empirical evidence on how interventions to reduce commissions affect the distribution of financial products.

This paper provides the first estimates of the impact of a major policy reform aimed at reducing commissions paid to brokers to sell financial products. We exploit a policy change that occurred on August 1, 2009, in which the Securities Exchange Board of India (SEBI) banned entry loads charged by all mutual fund firms operating in India. ${ }^{3}$ Prior to this reform, mutual fund firms used entry loads primarily to pay commissions to brokers who sold their products. The stated goal of the

\footnotetext{
${ }^{1}$ Carlin and Robinson (2011), Cole et al. (2011), Hastings and Mitchell (2011), Cole and Shastry (2010) present evaluations of financial literacy programs in a variety of contexts. For a recent review of financial literacy programs see Hastings et al. (2012).

${ }^{2}$ Walsh (2005) references a 1995 Investment Company Institute report that shows that 63 percent of $12 \mathrm{~b}-1$ fees are used for compensation of broker-dealers and related expenses.

${ }^{3}$ An entry load, typically called a "front-end load" in the U.S., is a fee that is calculated as a percentage of the total investment made in the mutual fund. Entry loads are immediately deducted from the customer's investment at the time of investment.
} 
policy was to "empower the investor in deciding the commission paid to the distributors and also to ensure transparency in commissions paid for mutual fund products". ${ }^{4}$ This law change reduced the ability of mutual funds to pay broker commissions, as funds could no longer use the immediate income earned from an investor's entry load to pay out a commission to the broker who made the sale. $^{5}$

The ban on entry loads could have multiple potential impacts on flows in to mutual funds. If investors face high search costs, and the primary role of brokers is to reduce search costs, then the entry load ban could cause a reduction in flows (Sirri and Tufano, 1998). Consistent with this idea, the Indian mutual fund industry has argued strongly that the entry load ban has reduced flows in to mutual funds by limiting the ability of fund companies to pay commissions. One of the key theoretical arguments made by proponents of allowing mutual funds to charge fees to defray broker commissions (such as entry loads in India or 12b-1 fees in the United States) is that such fees actually reduce the total cost of mutual fund investments; broker commissions lead to a larger mutual fund sector that can take advantage of economies of scale and charge lower fees overall (Ferris and Chance, 1987). The validity of such an argument hinges on whether the charging of distribution fees, such as the entry loads studied here, actually leads to larger fund flows.

On the other hand, it is also possible that the removal of entry loads could lead to an increase in flows in to mutual funds. The entry load ban effectively caps the up front cost of investing at zero. To the extent that some investors would now choose to invest given this lower up front cost, it is possible that flows could rise. ${ }^{6}$ Further, the amount of money that actually enters the fund given a fixed investment will mechanically be higher under the entry load ban policy, as no money is deducted from the initial investment to pay the entry load.

We present three types of evidence to evaluate the impact of the entry load ban on Indian mutual fund growth. First, we present data on net-flows aggregated up to the industry level. We find that net flows in to mutual funds have declined dramatically following the imposition of the entry load ban. This initial evidence is consistent with Indian fund companies' claims that the entry load ban has diminished the ability of the industry to attract flows. It is important to note, however, that this analysis of aggregate data only involves a comparison of before and after the entry load ban;

\footnotetext{
${ }^{4}$ For newspaper accounts of the importance of entry loads as the primary source of commissions see (1) "MFs Look For Life Beyond Entry Load Ban," Times of India, July 19, 2010 (2) "Mutual Fund Industry Struggling to Woo Retail Investors," Business Today, February 2011 Edition.

${ }^{5}$ For example, suppose an investor invested 100 rupees in an Indian mutual fund prior to the law change. Typically a mutual fund would take 2.25 rupees out of this as an investment as an entry load and pay it to the broker who sold the product. The entry load ban prevents mutual fund companies from taking any of the investor's initial investment as revenue; the full amount of the investment must be invested in the fund on the investor's behalf. Thus, if the mutual fund company wanted to pay the broker a commission they would have to use other sources of funds to do so.

${ }^{6}$ This assumes there is not a major supply contraction; however, given that the marginal cost of managing an additional dollar is low, it seems unlikely that this policy change would lead to a substantial reduction in mutual funds available for investment.
} 
other time varying factors, such as investor sentiment, could equally explain such observations.

We next analyze a newly assembled monthly panel dataset on Indian mutual funds over the period April 2006 through June 2012 to test whether the entry load ban had a causal impact on fund growth. Our primary identification strategy is to exploit the fact that funds that charged high entry loads prior to the entry load ban were more strongly "treated" by the policy than funds that charged low entry loads; on average, funds in our high entry load group had their entry loads decreased from 2.22 percent to zero, whereas funds in our low entry load group only had their loads reduced from .42 percent to zero. To the extent that the policy had important impacts, we would expect them to be borne out more strongly in the group of funds that charged high entry loads prior to the reform versus funds that charged low entry loads.

We analyze two outcome variables on fund growth: assets under management and net flows in to funds. We show that pre-trends in both these variables are similar across the high load and low load samples prior to the imposition of the entry load ban, and thus argue that comparing the post policy outcomes in these two groups is a reasonable way to ascertain the policy impact. On assets under management, the results suggest that, if anything, the policy led to larger growth of assets in to funds that previously charged high entry loads. ${ }^{7}$ We also analyze the net-flow measure used in Sirri and Tufano (1998), although this measure is noisier in our case due to data availability. Again, we find that funds that charged higher entry loads prior to the policy change experience larger net flows after the entry load ban than funds that charged low entry loads prior to the ban. Both of these findings stand in contrast to the hypothesis that the entry load ban has played an important causal role in the aggregate decline in net flows during the post entry load ban period.

One weakness of the comparison between high versus low entry load funds is that entry load levels were endogenously chosen prior to the ban, and thus it is possible that differences in the ex-post net flows of these funds are determined by other time varying factors independent of the entry load ban. While we are comforted by the fact that pre-trends in assets under management and returns were similar across these two groups in the sample of all funds, we next conduct an analysis of fund growth specifically within the subset of index funds. We argue that it is unlikely that there are divergent trends in unobservables for index funds around the period of the policy change given that all index funds are reasonably homogenous products (Hortacsu and Syverson, 2004). We show that the pre entry-load ban trends in assets under management, returns, and net flows for index funds were very similar across high and low load funds. We find that, in most specifications, high entry load index funds had very similar assets under management and net flows to low load index funds after the entry load ban. Overall, our analysis of index funds leads us to conclude that the

\footnotetext{
${ }^{7}$ Assets under management within a fund change over time for two reasons. First, the assets in the fund appreciate in value due to fund returns. Second, the fund grows due to inflows and outflows. In our comparisons the first effect is effectively controlled for by the fact that trends in the average returns in high entry load versus load entry load funds, excluding fees, were essentially the same both before and after the reform.
} 
entry load ban did not have a substantial impact on fund growth.

The main empirical results suggest that the entry load ban was not a major factor in the large general decline in net flows to the Indian mutual fund industry in the post entry load ban period. In our last section we provide some speculative evidence on why net flows in to Indian mutual funds declined in the post-reform period. Using newly available, nationally representative, data on household financial decisions in India, we show that there has been a substantial increase in investments in real assets (primarily gold and real estate) during the period following the entry load ban. We argue that Indian investors, similar to investors around the world, have generally shifted their money away from financial assets such as mutual funds towards real asset classes in response to the financial crisis of 2008, and would have likely done so even in the absence of the entry load ban.

We make two primary contributions. First, this paper is, to our knowledge, the first analysis of a major policy intervention that attempted to limit the ability of financial product providers to pay commissions to brokers. Given the rise in importance of such policies (such as the UK and Australian commissions bans mentioned above), as well as the longstanding debate in the United States on the investor welfare implications of $12 \mathrm{~b}-1$ fees, we believe our results will be useful for other policymakers considering the regulation of mutual fund distribution fees. Based on our findings, the primary explanation for the drop in net-flows in the Indian mutual funds sector observed in the period after the entry load ban appears to be a move from financial assets towards real assets, as opposed to the removal of incentives for distributors to sell mutual funds.

Second, our paper is the first to exploit a natural experiment strategy to evaluate the impact of mutual fund fees that are earmarked for distribution expenses (such as $12 \mathrm{~b}-1$ fees in the U.S.). ${ }^{8}$ Previous work has typically studied the correlation between fund flows and the level of $12 \mathrm{~b}-1$ fees or other broker compensation, controlling for all other observable fund characteristics. ${ }^{9}$ These studies have found that funds that charge 12b-1 fees or other sales loads do generally experience

\footnotetext{
${ }^{8}$ One important difference between the entry loads we study here and $12 \mathrm{~b}-1$ fees is that entry loads are charged to the investor at the time of investment, while $12 \mathrm{~b}-1$ fees are an annual recurring expense. Both types of fees are similar, however, in that fund companies are forced to meet distribution expenses out of monies raised through these fees exclusively.

${ }^{9}$ The majority of the previous work finds a positive relationship between sales loads and fund flows. Christoffersen et al. (2012) uses unique data on commission levels, including the share of loads that brokers receive as commissions, to show that funds with higher commission levels attract greater flows and have lower subsequent performance. Barber et al. (2005), Zhao (2008), Bergstresser et al. (2009) and Walsh (2005) find that, conditional on many observable characteristics, funds that charge higher 12b-1 fees grow faster. However, Ferris and Chance (1991) and Trzcinka and Zweig (1990) find no significant relationship between 12b-1 fees and fund flows; their data cover shorter periods of time and thus suggest that the relationship between sales loads and flows is time varying. The earliest work on the relationship between sales loads appears to be Friend et al. (1962), who found a positive correlation between sales loads and fund flows in the United States during the period 1952 through 1958 (Christoffersen et al., 2012). A related literature studies the impacts of commissions on real estate broker behavior, although none of these studies evaluate the impacts of law changes on the level of commissions that brokers can charge (Jia and Pathak (2009), Levitt and Syverson (2008)).
} 
greater growth. While we find these previous results persuasive, it is possible that there are unobservable factors, correlated with $12 \mathrm{~b}-1$ fees, that partially drive the relationship between fees and fund flows. For example, funds that charge higher 12b-1 fees might attract differentially less sophisticated investors, and the behavior of less sophisticated investors might differ from the behavior of sophisticated investors for other reasons besides sales loads. The entry load ban imposed by the Indian government constitutes an exogenous shock to the ability of high entry load funds to charge entry loads; we exploit this exogenous drop in entry loads for these funds to estimate the causal impact of distribution fees on fund flows. Another strength of the natural experiment approach is that we can include fund fixed effects, and exploit the within fund change in fees due to the policy; previous work typically does not include fund level fixed effects.

The paper proceeds as follows. Section 2 presents background information on the Indian mutual funds industry and the entry load ban. Section 3 presents a basic framework for evaluating the impact of commissions bans. Section 4 describes the data sources and presents the trends in fund flows. Section 5 presents the empirical methodology and the results. Section 6 provides evidence on household participation in asset classes other than mutual funds. Section 7 concludes.

\section{The Indian Mutual Funds Industry and the Entry Load Ban}

Indian mutual fund assets in 2009 amounted to approximately U.S. $\$ 90$ billion. ${ }^{10}$ While the size may be $1 / 100$ th the size of the US mutual fund industry ${ }^{11}$, assets under management in India have seen a real growth rate more than double that of the growth rate of assets under management in the United States (12 percent average annual real growth in assets under management in the Indian mutual fund industry since 1997, versus 5.3 percent real average annual growth in the U.S.). ${ }^{12}$ There are approximately 10 million mutual fund investors in India (Halan, 2010), and about 40 asset management companies. Assets in Indian equity-oriented mutual funds constitute approximately seven percent of the market capitalization of the Bombay Stock Exchange.

As in the United States, a large fraction of mutual fund sales comes through a network of thousands of mutual fund intermediaries known as Individual Financial Advisors (IFAs) and brokers (Kamiyama, 2007). ${ }^{13}$ There are approximately 92,000 IFAs in India, and in 2007 they mobilized 57 percent of new assets under management to mutual funds. There are approximately 2.5 million

\footnotetext{
${ }^{10}$ The India Rupee/U.S. dollar exchange rate taken from finance.yahoo.com on Monday, October 26, 2009.

${ }^{11}$ These data come from the 2009 Investment Company Fact Book which is produced by the Investment Company Institute (the trade association of mutual funds and other asset management companies in the United States). We include mutual funds and closed-end funds for comparability with the Indian data.

${ }^{12}$ Growth rates of assets under management calculated from monthly reports of the Association Mutual Funds in India monthly reports.

${ }^{13}$ Bergstresser et. al (2005) estimate that U.S. investors paid 15.2 billion dollars in distribution fees in 2002, which are not much less than the 23.8 billion dollars spent on management fees in that same year.
} 
insurance agents in India, some of whom also sell mutual fund products. The sales process typically worked as follows in the period before the entry load ban policy was initiated. An individual investor would pay the amount they wanted to invest, say 100 rupees, to the IFA. The IFA would transfer this whole amount to the mutual fund company, which would then deduct the entry load (typically 2.25 percent) and invest the remaining 97.75 rupees in the mutual fund. The 2.25 rupee entry load would then typically be sent back to the IFA as compensation.

Prior to the entry load ban of August 2009, the amount that mutual fund companies could spend on distribution expenses was capped at the total amount of entry loads brought in to the fund (Chanda, 2006). Funds were not allowed to use income from annual operating expenses or exit loads to pay commissions to meet distribution costs, including payments to brokers. The rationale for this rule was that new investors should be charged for the costs of distribution, as they are the primary beneficiary of any distribution costs. While most funds paid the broker an amount equal to the entry load, funds were allowed to save revenue from entry loads over time and use those monies to pay commissions in the future.

On June 30, 2009, the Securities and Exchange Board of India (SEBI) announced that starting on August 1, 2009, mutual funds would no longer be allowed to charge entry loads. Specifically, the law change had three components:

1. Funds could not deduct any amount of an investor's initial investment (entry load ban)

2. Funds could charge up to 1 percent of redemptions ("exit loads") and use these to pay commissions

3. Distributors had to disclose any commissions paid to them

The most important impact of this policy is that it directly reduced the source of funds that mutual fund companies could use to pay distribution costs (item (1)). Funds were no longer allowed to charge investors directly, at the time of investment, and use those proceeds to pay brokers or other distribution costs. Instead, funds had to rely on two other funding sources to pay distribution costs. First, as noted in item (2), funds could use fees collected by investors at the time of exit to meet distribution costs. Second, funds could use any monies saved from entry loads charged in the past to meet current distribution costs. ${ }^{14}$ We study the impact of this exogenous change in the sources of funds that Indian mutual fund companies could use to meet distribution costs.

Unfortunately, there is no publicly available disaggregated data on the amounts of commissions brokers received from mutual fund companies. Contracts between brokers and the mutual fund

\footnotetext{
${ }^{14}$ These funds are called the fund's "unutilized load balance." Fund companies were allowed to use as much of this unutilized load balance (including unutilized entry and exit loads) to pay commissions as they wished after the policy change. On March 9, 2011, SEBI instituted a rule that funds were not allowed to use more than one third of the unutilized load balance as of July 31, 2009 for commissions in any given year (Securities and Exchange Board of India, 2012b).
} 
companies are proprietary and fund companies seem wary to release such information. However, the available aggregate data suggests that commissions have declined substantially in the post entry load ban period. Shah et al. (2010) report estimates that the average commissions paid to brokers equaled 1.78 percent of the initial investment in 2008, 1.39 percent in 2009, and .94 percent in the first quarter of 2010. Shah and Kant (2011) note that, according to mutual fund industry executives, commissions have come done from approximately 1.2 to 1.5 percent to approximately .75 percent after the entry load ban. This decline is unsurprising, given that the typical Indian mutual fund charged 2.25 percent in entry loads prior to the ban and used all of that income to pay brokers. ${ }^{15}$

SEBI had two primary motivations for enacting this policy. First, SEBI argued that investors were generally not aware of entry loads, and thus made sub-optimal decisions when choosing mutual funds. ${ }^{16}$ SEBI envisioned a market where the customer would directly pay the broker for advice, instead of the broker being compensated by the mutual fund company via an entry load. ${ }^{17}$ Second, SEBI believed that entry loads gave brokers an incentive to encourage investors to move in and out of different mutual fund investments too frequently; removing entry loads would remove the incentive for brokers to "churn" investors in this manner. ${ }^{18}$

There has been an active policy debate surrounding the entry load ban policy since its inception. The policy was further tweaked in September 2011 when fund houses were allowed to charge the customer 100 rupees at the time of investment, and pass this on to the broker as a commission. ${ }^{19}$ In August 2012, SEBI further changed the mutual fund fee policy with the goal of forcing funds to use income from annual expense charges instead of exit loads to pay commissions. SEBI argued that fund companies had an incentive to encourage investor exit under the current regime. ${ }^{20}$

\section{Mutual Fund Flows and Commissions}

We present a simple framework to illustrate the impacts of a policy that reduces the ability of mutual fund firms to pay commissions to brokers. We consider how this policy change might affect

\footnotetext{
${ }^{15}$ Shah and Kant (2011) also quote Dhruva Chatterji, an analyst at Morningstar India: "After the ban on entry load, asset management companies are now compensating the upfront commission to distributors. However, their ability to pay from their pockets is getting limited due to depleting reserves. The upfront commission has already come down from what it was at the time of the entry-load ban and it is likely to go down further."

${ }^{16}$ In essence, SEBI argue that entry loads are a shrouded fee in the sense of Gabaix and Laibson (2006), Koszegi et al. (2012), Anagol and Kim (2012).

${ }^{17}$ Although no systematic data exists on the prevalence of investors making direct payments to brokers for advice, anecdotal evidence suggests that this has been very uncommon.

${ }^{18}$ Studying the impact of the entry load ban on "churning" is an interesting avenue for future research. We do not address this question in this paper as we do not have access to investor level data to actually measure the amount of churning individuals did before and after the policy change.

${ }^{19}$ For new customers, fund companies could charge up to 150 rupees to pass on to the broker as commission.

${ }^{20}$ For details on the August, 2012 reform see Securities and Exchange Board of India (2012a).
} 
the behavior of two stylized types of customers. We first consider customers who face high search costs on their own, and thus can only locate mutual funds with the help of a broker. In this case customers are directly influenced by the recommendations made by brokers. We show that the entry load ban could cause these types of customers to invest less in mutual funds.

We also consider the behavior of customers who do not require help in choosing a fund, but have to go through the broker to execute their decision. In this case brokers mainly serve to process the investment transaction, but do not have a causal influence on what product the customer actually chooses. In this case, it is possible that flows in to funds could rise due to the entry load ban, as these customers can now avail of broker services without paying entry loads. ${ }^{21}$

\subsection{Customers that Need Brokers to Locate Funds}

In this model clients can only observe mutual funds through brokers. The broker chooses the number of clients to market mutual funds to. ${ }^{22}$ The broker faces a cost $k(e)$ that is a function of his effort $e$, in trying to sell to customers. We assume that $e \geq 0$ (effort must be zero or positive), $k(0)=0$ (zero effort has zero cost), $k^{\prime}(e) \geq 0$ (the cost of selling is increasing in effort), and $k(e) \rightarrow \infty, e \rightarrow \infty$.

The broker is remunerated for his effort by the product provider, i.e. the mutual fund company in our case. We assume that there are two kinds of products: a high commission product $H$ with a commission of $t_{H}$, and a low commission product $L$ with a commission of $t_{L}$. We assume that $t_{H}>t_{L}$, and that brokers take $t_{H}$ and $t_{L}$ as given. These two products can be thought of as the high and low entry load funds that existed prior to the entry load ban.

Brokers benefit from selling a mutual fund product in two (related) ways. First, the broker earns commissions from the product provider for every sale. Second, the broker may also benefit from future sales of funds to the same customer; the ability of the broker to earn these future sales depends on the suitability of advice he gives in the first interaction. We first analyze the case where brokers only care about the initial commission earned, and then consider the case where brokers have dynamic incentives as well.

\footnotetext{
${ }^{21}$ Brokers might still choose to serve these customers because the mutual fund company pays them a commission out of other funds besides entry loads.

${ }^{22}$ These clients could either be individuals who had made investments with the broker in the past, or individuals who the broker seeks who have not made investments in the past. While this is an important distinction from the perspective of stock market participation, our data does not allow us to distinguish flows from these two types of investors so we abstract from this detail in the model.
} 


\section{Case 1: Commissions Only}

We first study the case where brokers do not care about the suitability of products, and instead only focus on the up-front commissions they earn for selling the product. In this case the broker gets paid $t_{i}$ for every unit of product $i$ sold. The broker chooses his effort level $e$ to maximize the following profit function:

$$
\pi=t_{i}-k(e)
$$

The broker's first order condition is $k^{\prime}(e)=t_{i}$, which sets the marginal cost of effort equal to the marginal revenue from selling an additional product $t_{i}$. The higher the commission amount, the more effort brokers will put in to selling the product. Conditional on putting in effort to make a sale, the broker will clearly always prefer to sell product $H$ over product $L$, as the commission is higher on product $H$. If the commissions ban implies that $t_{i}=0$, then the broker will not exert any effort in soliciting clients and fund flows will fall.

\section{Case 2: Suitability Concerns and Commissions}

We use the model of Ottaviani and Inderst (2011) to illustrate the impact of a commissions ban when the broker cares about the suitability of the product for the customer. In their set-up, there are two customers, $A$ and $B$, and two products, $H$ and $L$. Product type $H$ is suitable for customer type $A$ and product type $L$ is suitable for customer type $B .{ }^{23}$ For simplicity, the model assumes that the commission on product $L, t_{L}=0$. In our case, it is natural to think of the high commission product $(H)$ as the funds that charged high entry loads prior to the entry load ban, and the low commission product (type $L$ ) as the funds that charged low entry loads prior to the entry load ban. The broker's payoff in terms of suitability, not including commissions, is equal to $\bar{v}$ when the broker recommends the correct product to the consumer, and $\underline{v}$ when the broker recommends the incorrect product to the consumer. The broker receives a higher suitability payoff when he recommends the correct product versus the incorrect product: $\bar{v}>\underline{v}$. The broker believes with probability $q$ that the high commission product $H$ is correct for the consumer in terms of suitability. The broker will sell product $H$ when the expected payoff from selling $H$ is greater than that of selling $L$ :

$$
t_{H}+q \bar{v}+(1-q) \underline{v} \geq q \underline{v}+(1-q) \bar{v}
$$

The broker chooses to recommend the high commission product $H$ if his belief $q$ is greater than

\footnotetext{
${ }^{23}$ Customer type $A$ might be an active investor who is trying to find actively managed funds that beat the market, while customer type $B$ prefers a passive strategy of investing in index funds.
} 
the following cut-off point:

$$
q *=\frac{1}{2}-\frac{t_{H}}{2 \rho}
$$

where $\rho=\bar{v}-\underline{v}$.

As the value of the commission on product $H\left(t_{H}\right)$ increases, the cut-off where the broker begins to recommend the more suitable product decreases. In other words, conditional on the broker's beliefs about suitability $q$, the broker is more likely to recommend the $H$ type product as the commission on that product is increased. The policy experiment we study in this paper is similar to a comparative static where we exogenously reduce the commission on product $H$. In this case the cut-off value for recommending the $H$ type product increases, and we expect that, conditional on the broker's beliefs about suitability $q$, the broker will be less likely to recommend the high commission product. Thus, even when brokers have a concern for suitability, the exogenous change in commissions could reduce the flows in to the high entry load funds.

\subsection{Customer Observes the Product Directly}

In the model above we have assumed that customers need brokers to educate them about the different types of product on the market, and that brokers have a causal impact on customers' choices between high and low commission products. We now introduce a class of sophisticated customers $S$ who observe mutual funds without the effort of the broker, and choose to buy the product without the broker's intervention. These customers, however, do have to pay the commission as this is the only distribution channel for the product. ${ }^{24}$ These customers simply choose the product that offers the highest expected return:

$$
u=R\left(X-t_{i}\right)
$$

where $X$ is the amount invested, $R$ is the return on the product and $t$ is the upfront commission deducted.

There are two reasons why the entry load ban might lead to an increase in flows to funds that had high entry loads prior to the ban. First, in the event of a commissions ban that sets $t=0$, none of the investors' money gets deducted to pay an entry load, and thus a greater amount enters in to the fund. In other words, if investors continued to invest the same amount in to the high entry load funds after the ban, the net flows in to the those funds would increase because entry

\footnotetext{
${ }^{24}$ As of January 2008 all mutual fund companies were required to allow investors to invest directly with the fund company as a way of avoiding entry loads (Securities and Exchange Board of India, 2007). Approximately seven percent of assets under management in Indian mutual funds, as of March 2010, came through this direct route (Shah et al., 2010). Customers who were sophisticated enough to know about this direct route should not be affected by the entry load ban policy, as they were not paying entry loads even prior to the policy. However, customers who were not aware of the direct route might have avoided investing in high load mutual funds prior to the entry load ban.
} 
loads were no longer being deducted. Second, given that the price of investing $t$ has gone down, we expect there will be a substitution effect away from other savings products and consumption items towards mutual funds.

\subsection{Aggregate Impact of Entry Load Ban}

Overall, the impact of the entry load ban on flows in to mutual funds depends on the relative importance of the investor types discussed above. If most investors' decisions are directly influenced by broker commissions, then it is plausible that the entry load ban could lead to a decline in net flows. On the other hand, if the mutual fund choices of consumers are not affected by broker incentives, then it is possible that flows will increase due to the fact that lower loads mean greater inflows mechanically, and because investors will substitute in to lower load products.

\section{Describing Indian Mutual Fund Flows}

\subsection{Aggregate Data on Indian Fund Flows}

We begin our empirical analysis of the entry load ban by presenting data on the aggregate evolution of flows in to Indian mutual funds. Figures 1 and 2 show the levels of net-flows, inflows, and outflows to existing equity open-ended mutual funds around the policy change studied here. This data was obtained from monthly reports posted at the Association of Mutual Funds of India (AMFI) website. The vertical dashed line indicates August 2009, the date of the ban on entry loads. Overall, the pattern of net flows in the pre-period follows the level of the Sensex stock exchange more closely than in the post-reform period, and flows in to mutual funds appear to be lower in the post reform period versus the pre-reform period.

This pattern of net-flows is consistent with a variety of underlying patterns in inflows and outflows, so Figure 2 separately plots inflows and outflows. The plot of inflows shows that there are still substantial inflows into mutual funds in the post-policy reform period, however the inflows do not seem to follow the market closely relative to how inflows followed the market in the pre-reform period. Outflows continue to follow the market closely in the post-reform period. These figures suggest that the fall in net flows in to Indian mutual funds in the post entry load ban period has primarily been due to a change in the amount of inflows, as opposed to an increase in outflows (relative to the stock market).

Another potential measure of investor participation in Indian mutual funds is the number of retail mutual fund accounts. Figure 3 presents the number of retail investor accounts. After the 2009 ban, there has been an approximately 9.4 percent decline in retail accounts. 
Overall, the aggregate data suggests that mutual fund growth declined after the entry load ban was implemented. It is important to note, however, that the results in these plots conflate the impact of the entry load ban with all other time varying market conditions. It is difficult to conclude from these aggregate plots alone whether the entry load ban has had a causal impact on flows in to mutual funds.

\section{Empirical Analysis of Fund Level Data}

In this section, we use fund level data to investigate whether the substantial drop in inflows in to Indian mutual funds is due to the entry load ban imposed in August 2009.

\subsection{Creation of Fund Level Data Set}

We hand construct a new monthly data set of fund level net flows, assets under management, fees and other fund characteristics for the Indian mutual funds sector. For the period April 2006 through September 2010 the AMFI website lists the average assets under management for each Indian mutual fund in that month. From October 2010 through June 2012 average assets under management are reported on a quarterly basis. ${ }^{25}$ We downloaded each of these listings and merged them over time to create a panel data set of average assets under management for each fund in each month. This constitutes our base sample of fund*month observations.

Our analysis focuses primarily on equity mutual funds. Equity mutual funds are the only set of funds where commissions motivated sales agents are likely to be important. In the Indian market debt mutual funds are primarily invested in by corporations. Due to tax reasons, corporations use debt mutual funds for short term cash management. For example, as of March 2011 only 5.01 percent of the assets under management in debt type schemes was owned by retail investors. ${ }^{26}$ However, for equity oriented schemes the percentage owned by retail investors is 64.2 percent. $^{27}$

Given our focus on equity mutual funds, we delete all non-equity fund observations, as well as any funds that appear to only serve institutional investors. Deleted funds are primarily a large number of short term mutual funds that Indian firms use for cash management. The data appendix reports the specific terms we searched on within the fund title to determine which funds to eliminate from

\footnotetext{
${ }^{25}$ For the period when only quarterly data on assets under management are available, we linearly impute values for the months where was not reported.

${ }^{26}$ Statistics calculated from Table 1 Asset Under Management and Folios - Category Wise - Aggregate - As on March 31, 2011 on the AMFI website (www.amfiindia.com). Debt type funds include liquid/money market funds, gilt (government bond) funds, and debt-oriented schemes.

${ }^{27}$ Equity type funds include equity oriented mutual funds, balanced mutual funds, Gold ETFs, and ETFs other than gold.
} 
the sample. The set of funds remaining after removing the non-equity funds constitutes our primary sample of individual fund level data. In addition to removing debt funds, our primary data set also does not include closed-end funds. Closed-end funds cannot take in new money after they are started, and thus they are constrained to have a net flow rate of less than zero. We attempted to keep all funds that invested any proportion of their assets in equities; we present our empirical results both including and excluding funds that invested a small amount in equities. In total, we begin with 65,533 fund*month observations on average asset under management from the AMFI website.

We next merge the data set of average assets under management to data on net asset values obtained from two sources. For the period April 2009 through June 2012 we use net asset value data from the AMFI website. Ideally we would have liked to obtain the net asset value data from the AMFI website for all months, but unfortunately AMFI only makes its historical net asset value data available starting in April 2009. We download the net asset values of funds on the first day of the calendar month where data from all funds was available. ${ }^{28}$ We then merge the net asset value data on to the assets under management data. 37,143 observations on net asset value successfully merge to fund level observations on assets under management. There are 1,852 fund*month observations on net asset values from the AMFI website that do not have a corresponding entry on assets under management; given that we do not have information on the assets under management for these funds in those months, we drop them from the sample.

For the period April 2006 through April 2009 we use data on net asset values from the ACE database, a proprietary database on Indian mutual funds. We first manually created a crosswalk between the names of the funds in the AMFI assets under management data and the names in the ACE database. 35,656 of our observations on assets under management are successfully merged to net asset values for the period April 2006 through April 2009. There are 4,990 observations on net asset values in the ACE data for which we do not have the corresponding assets under management from the AMFI database; these observations are dropped from the analysis.

The last important piece of data we need on funds is the level of fees charged. Indian mutual funds charge three types of fees. Entry loads are collected as a percentage of an investors initial investment. Management fees are collected on an annual basis as a percentage of the total assets held in the fund. Exit loads are collected as a percentage of the amount withdrawn from the fund. ${ }^{29}$ We collected fee data as follows. First, most Indian mutual fund companies post monthly historical fact-sheets on their funds at their websites. We manually went through these monthly fact-sheets

\footnotetext{
${ }^{28}$ Occasionally the first day of the month is not a trading day, and thus some funds do not report net asset values on those days. In this case, we use the data closest to the first day of the month.

${ }^{29}$ In the early part of our data some funds charged a contingent deferred sales charge (CDSC), which is a fee that is charged if the investor withdraws their investment within a certain amount time. Given that these are essentially the same as exit loads (which are also typically only charged if the investor exits within a certain amount of time), we include the CDSC data as exit loads.
} 
and collected data on the entry loads and exit loads charged for each fund. Using this method we are able to obtain the historical entry and exit load data for 39,642 (59.8 percent) of our fund level observations.

For the remaining funds, we took two approaches to filling in their entry load, management fee, and exit load information. First, for a limited set of these funds, the ACE database contained a snapshot of the entry and exit loads charged as of August 2009, the last month before the entry load ban. We assume that the fund charged these entry loads and exit loads for all periods it was in existence prior to the entry load ban. We believe this assumption is reasonable given that for the funds where we have fact-sheet information, it was rare that a fund would change the fee structure for the same fund over time (besides those changes that were mandated by the entry load ban). For funds that did not have either historical fact-sheet information or the fee information from the ACE database, we manually searched for the funds initial offer documents. These offer documents contain the fees the fund intended to charge in the future. Using all of these methods we are able obtain entry load data for 98 percent of the funds in our sample.

We study two primary outcome variables to measure the impact of the entry load ban on fund growth. First, we look at how assets under management have evolved after the entry load ban. Assets under management within a fund change for two reasons. First, the value of the existing assets in the fund change based on the return earned on the securities within the fund. Second, investors purchase and sell units of the fund. We show that the trends in returns earned on high entry load and low entry load funds were very similar throughout our whole period, and thus any comparison of assets under management across these two groups essentially already controls for changes in returns over time. The main advantage of the assets under management variable is that it is consistently and cleanly measured for all of the funds in our sample.

We also present results on the measure of fund growth, Net Flow $i, t$, as defined in Sirri and Tufano (1998):

$$
\text { Net Flow } i, t=\frac{\operatorname{AUM}_{i, t+1}-\left(1+R_{i, t}\right) \mathrm{AUM}_{i, t}}{\mathrm{AUM}_{i, t}}
$$

$R_{i, t}$ is the return, excluding fees, earned on the securities held by the fund. $A U M_{i, t}$ is fund $i$ 's assets under management at time $t$.

This net flow measure displays a significant amount of noise over time, even when we average across a large number of funds. The main issue appears to be that our assets under management measure is an average of the assets under management in the fund within a month. However, our returns measure is based on the return in the fund from the first day of the month to the first day of the next month. This mis-match can lead us to systematically over-estimate net-flows in one 
month and underestimate net flows in the next. Unfortunately, without daily data on assets under management, there is no way for us to determine to what extent the noise in this measure is due to this measurement issue.

Another important issue with this definition of net flows is that, in cases where a fund has very small total net assets in the prior period, and large growth, it can produce very large net flow measures that are not necessarily indicative of fund growth. We therefore choose a trimmed sample as our baseline sample, where we remove the top and bottom one percent of observations in terms of net flows. In practice this means that funds with net flow growth rates of less than 88 percent, or greater than 350 percent, are excluded from the sample. Figure 4 shows the histogram of net flows after the top and bottom one percent of observations have been trimmed.

\subsection{Methodology}

Our primary empirical methodology in this paper is to compare the impact of the entry load ban on funds that charged high entry loads prior to the ban versus funds that charged low entry loads to the ban.

Figure 5 presents the distribution of month*fund observations across the levels of entry loads observed in the data in the pre-reform period. The figure shows two important mass points, one at the zero entry load point, and one at the 2.25 entry load point. For simplicity, we thus define two types of funds prior to the reform. High entry load funds are defined as those funds that charged an average entry load of 2.25 percent or higher prior to the reform. Low entry load funds are those funds that charged an average entry load of less than 2.25 percent prior to the reform. We test whether high entry load funds have attracted differentially more or less net flows after the imposition of the entry load ban.

Our results include all funds that were in existence prior to the reform. Funds that appear in our data but then exit prior to the reform are categorized as high or low entry load based on the level of entry load they charged prior to the reform. We believe these funds are useful observations on how

entry loads impacted flows prior to the law change. However, it is not possible to categorize funds that were started after the entry load ban as high or low entry load funds, as they were mandated by law to have zero entry loads. These funds are dropped from our analysis as well.

\subsection{The Impact of the Entry Load Ban on All Fund Flows}

Table 1 presents summary statistics on high and low entry load funds from the beginning of our data (April 2006) through the implementation of the reform in August 2009. The average entry load charged by high entry load funds is 2.22 percent, whereas in the low entry load fund group 
it was .42 percent. The difference in entry loads charged by high versus low entry load funds is statistically significant at the one percent level; this is consistent with the idea that the entry load ban will have a stronger effect on high versus low entry load funds. Figure 6 plots the average entry load charged by funds in our high entry load group and our low entry load group. The figure shows that average entry loads were essentially flat at approximately two percent prior to the reform, and then experienced a discrete and large drop to zero after the reform. In the low entry load group, the average entry load was slightly declining over time prior to the reform.

The mean size of funds in the high entry load group was 44.2 million dollars, where as the mean size of funds in the low entry load group is 22.2 million dollars (significantly different at the one percent level). Net flows in to both types of funds were both equal to approximately 4 percentage points per month; these are not statistically different prior to the reform.

The mean return (before any expenses) in the high entry load group is 15 basis points higher per month than in the high entry load group, and this difference is significant at the one percent level. However, the groups have had a very similar time pattern of returns. Figure 7 plots the mean return, by month, for the high entry load and low entry load groups separately. Note that the scale for the high entry load funds is on the left y-axis, and the scale for the low entry load group is on the right y-axis. The returns in the high entry load group are more volatile than the low entry load group, but the trends are nearly identical. This figure shows that, at least in terms of returns (which is arguably the most important product characteristic of a fund), there do not seem to be important trend differences across high and low entry load funds prior to the entry load ban. Thus, any difference we might see in fund growth across these two types of funds after the policy reform were not driven by a major change in return performance after the policy change.

Table 2 shows the proportion of pre-reform observations that are in ten major categories of Indian funds. In both groups the most common type of fund are general equity funds, which invest in a variety of equity instruments. Sector funds are those that focus on specific sectors such as infrastructure, banking, agriculture etc. Balance funds are funds that invest a substantial portion of assets in debt as well as equities. It is important to note that the allocation of the low entry load funds across these fund categories is substantially different from the fund categories in the high entry load group. There are two major differences between the distribution of low entry load and high entry load funds across these categories. First, approximately 15 percent of the low entry load observations are index funds, while only 3.6 percent of the high entry load funds are index funds. Second, 31 percent of the low entry load group are "Income" funds. These are funds that primarily invest in debt securities, but allocate a small (unobserved) proportion to equities. We suspect that these funds have lower entry loads because they catered to more sophisticated investors who were interested in avoiding fees, although we do not have data on investor characteristics to test this. We present our main empirical results both with and without the "Income" fund group to make 
sure any differences we find are not being driven by this specific group of funds alone.

Before presenting regression based results on the impact of the entry load ban on fund growth in our two groups of funds, we first present simple graphical evidence on how fund growth has evolved in these two types of funds over time. The left panel of Figure 8 plots the mean logarithm of assets under management for our high entry load and low entry load groups over the period of our sample. Given that these two types of funds have essentially the same trends in returns (Figure 7), we can use changes in assets under management as a signal of how fund growth has varied for the two types of funds. The trends in log assets under management in both groups prior to the reform are very similar. Both series peak in early 2008, hit a bottom in mid 2009, and show a large increase in the few months before the policy ban. Despite the fact that funds in the low entry load group were statistically and economically different from the high entry load group along a number of observable characteristics in the pre-reform period, these difference did not cause these two types of funds to have substantially different patterns of asset growth prior to the reform. Given the similarity in trends prior the reform, we argue that it is unlikely that any patterns we observe after the reform would be due to differential trends in unobservables.

The two types of funds do show some substantial differences in asset growth after the reform. In particular, in the seven months after the reform the low entry load funds experienced substantial growth in assets under management, while the high entry load funds experienced only minor growth. It is difficult know whether this initial difference was due to the policy change or just an extension of trends prior to the reform. What is striking, however is that beyond this initial period of seven months after the reform, both groups have experienced low asset growth. And, in particular, the asset growth has been lower in the low entry load group relative to the high entry load group. This result is not consistent with the idea that the Indian mutual industry's general lack of growth in the period after the reform was caused by the entry load ban. The right panel of Figure 8 plots the average assets under management in both groups, but now excludes all of the "monthly income plans," which were funds that typically charged low entry loads and invested only a small proportion of their portfolios in equities. The same general pattern of low asset growth in the post reform period emerges in this sample as well.

Note that, as show in Figure 7, monthly returns in the post reform period were generally positive, so the fall in assets under management in both types of funds signals that there were substantial negative flows out of mutual funds during the post-reform period. What is interesting, however, is the fact that both high and low entry load funds experienced drops in asset growth. This result is inconsistent with the hypothesis that the entry load ban had an important impact on fund growth. If anything, this result would be consistent with investors moving money out of low entry load funds and in to high entry loads. Such a strategy would make sense given that in the pre-reform period high entry load funds did experience higher average returns. However, given that we do not 
have investor level data, it is not possible for us to directly test whether investors did move funds from previously low entry load funds to previously high entry load funds.

Figure 9 shows the average monthly net flows as calculated in Sirri and Tufano (1998). The series is much noisier than the assets under management series, perhaps because of the mis-match between our assets under management data and the returns data described earlier. As was shown in the summary statistics, the mean net flow for both groups is close to zero, although there is substantial variation in net flow rates over time. Given the noisiness in this measure over time, it is difficult to visually compare the pre-trends using this outcome measure. Perhaps the one discernable pattern is that starting in early 2008 both groups see a decline in net-flows (on average), and then both groups display an increase in net flows starting in early 2009. It is quite clear, however, that after the policy change net flows in to low entry load funds have declined substantially relative to net flows in to high entry load funds. The right panel of Figure 9, which shows the figure excluding income funds, shows a similar pattern. This result is inconsistent with the hypothesis that the entry load ban has caused a decline in mutual fund growth in the high entry load group alone.

\subsection{All Funds: Empirical Results}

The figures above showed that, in terms average asset growth, funds that had high entry loads prior to the reform have fared better than funds that charged low entry loads after the entry load ban. While the figures suggest that the entry load ban was not a major cause of the Indian mutual industry's negative net flows in the post reform period, Tables 1 and 2 did show that there were a number of differences across the high and low entry load groups that it would be useful to control for in comparing their post-reform asset growth. We now turn to a regression approach where we explicitly control for all time invariant fund characteristic differences across these two groups (using fund fixed effects), as well as time varying characteristics such as return performance, which should be important in explaining asset growth at the fund level. These tests allow us to determine whether the negative impact of the entry load ban on mutual funds might be obfuscated by the fact that other important changes occurred across these two groups during our study period.

Our primary statistical results are produced using the following estimating equation where we separately estimate the impact of the entry load ban on high versus low entry load funds:

$$
\begin{aligned}
\mathrm{Y}_{i, t}=\beta_{0}+\beta_{1} \text { Post Reform*High Entry Load } & \text { Fund }_{t}+\beta_{2} \text { Post Reform }_{t} \\
& +\beta_{3} \text { High Entry Load Fund }{ }_{i}+\beta P_{i, t}+\gamma_{i}+\epsilon_{i, t}
\end{aligned}
$$

$Y_{i, t}$ is our outcome variable (either log assets under management or net flows) for fund $i$ in month

t. The variable Post Reform $t$ is an indicator for observations in months after the reform was 
implemented (August 2009 and afterwards). The variable High Entry Load Fund $i$ is an indicator for those funds that charged a positive entry load before the policy's implementation. We are interested in estimating $\beta_{1}$, which is the difference in our outcome variable across high versus low entry load funds in the period after the policy change.

$P_{i, t}$ is a vector of covariates that allow us to control for the affect of prior performance (potentially convex) on fund growth (Sirri and Tufano (1998)). $\gamma_{i}$ is a fund level fixed effect which controls for the fund type, fund's asset management company, and any other time invariant fund features. Note that the inclusion of the fund level fixed effect $\gamma_{i}$ means we are identifying the other coefficients in the model with variation in changes in past performance and entry load levels over time (as opposed to variation in entry loads across funds). Standard errors are heteroskedasticity robust and are clustered at the fund level.

Table 3 presents the results of these regressions where the dependent variable is the logarithm of assets under management. Column (1)includes no controls and is thus just a simple comparison of net flows to high versus low entry load funds after the entry load ban. This specification suggests that high entry load funds had lower assets under management in the post ban period. However, this result is only significant at the ten percent level, and this simple set of variables explains only 1.7 percent of the variation in assets under management.

Column (2) introduces fund level fixed effects, to determine whether the negative result we saw in Column 1 is driven by variation across funds as opposed to variation within funds induced by the policy change. The inclusion of fund level fixed effects moves the coefficient on the Post Reform*High Entry Load Func close to zero (-.063). The coefficient is not significant at standard significance levels. These fixed effects control for any fund specific characteristics that do not change over time, including the style of the fund (large cap, small cap, infrastructure, etc.) and the fund family (Fidelity, Tata, etc.). Note that in all of the remaining specifications we no longer estimate the coefficient on the "High Entry Load" variable as that effect is subsumed by the fund fixed effects.

Columns (3) introduces Month*Year fixed effects (i.e. a separate dummy variable for every month in the data). These fixed effects control for the common time variation across both groups apparent in Figure 8. The introduction of the these variables does not have an important impact.

Column (4) adds fixed effects for the interaction between the post reform period and the fund family the fund is a part of. The interactions account for changes in asset management that might happen differentially across funds in different fund families over time; it also accounts for any changes in marketing or other behavior at the fund family level over time. Prior work has typically included the average measure of the dependent variable across the family to control for family level effects, however Gormley and Matsa (2012) show that this approach can potentially lead to inconsistent estimates; they recommend using the interaction of a time variable and a fixed effect for the group 
of interest as is done here. The inclusion of time-varying family effects does not change our estimate of the program impact substantially.

We now introduce a measure of fund performance as an explanatory variable. This measure is defined as follows. For each month $t$ we calculate the fund's total return over the period $t-7$ through $t-1$ (i.e. the total return in the six months prior to the current month). We then define the variable Rank as the fund's percentile rank within it's fund category for that month. For example, a fund that was in the 10th percentile in its fund category based on its past six month returns would have a value of 10 for this variable. ${ }^{30}$ A fund in the 90th percentile would have a value of 90 . To allow for a potentially non-linear relationship between past fund performance, as shown in Sirri and Tufano (1998), we include two variables to measure this relationship as is done in Christoffersen et al. (2012). The variable Lag Ranked Returns Low is defined as $\min (.5$, Rank). The variable Lag Ranked Returns High is defined as Rank - Lag Ranked Returns Low. The inclusion of both these variables allows us to estimate a different slope on the performance variable below and above median performance.

Column (5) presents our results when we include a measure of past performance. The sample size in this Column is lower because we require six months of lagged return data to form the fund ranking variables. The coefficient on the Lag Ranked Returns Low is small and statistically insignificant. The coefficient on Lag Ranked Returns High is negative and significant, which suggests that funds that had high performance in the past six months have lower assets under management in the current month; this result is contrary to prior work that has typically found that greater past performance causes larger growth in fund assets. We suspect that this negative coefficient may be due to mean reversion in returns. Funds that had high performance in the past six months are likely to have higher assets under management coming in the current month, as well as lower performance in the current month due to mean reversion. Current month returns will affect our measure of assets under management because our measure is an average of the daily assets under management within the fund. This mean reverting behavior in returns can cause funds that had high performance in the past to appear to have lower assets under management in the current period. Irrespective of the explanation for this coefficient, the inclusion of this past performance variable has little impact on our estimate of the policy's differential impact across high versus low entry load funds. ${ }^{31}$

Table 4 presents the same specifications as in Table 3, however we now exclude the income type funds that were substantially more prevalent in the low entry load group (Table 2). This leads to

\footnotetext{
${ }^{30}$ The fund categories in our data are Index, Tax Savings, General Equity, Large Cap, Sector Fund, Bond Equity Mix, International, Small and Mid Cap, Balance, and Gold. We use broadly defined categories, similar to the six broad categories used in Christoffersen et al. (2012).

${ }^{31}$ We do not believe that this negative coefficient is due to measurement error, as when we use net flows as our dependent variable we do find the standard convex relationship between fund flows and prior performance.
} 
perhaps a more balanced comparison in terms of the fund categories represented in the low and high entry load groups. When income funds are excluded from the low entry load group, we consistently find positive estimates of $\beta_{1}$; if anything, assets under management grew in the previously high entry load group in the period after the entry load ban.

Table 5 presents our estimation results where we use net flows in to the fund as a measure of fund growth. Column (1) includes only the variables necessary to assess the differential impact of the policy change on the high and low entry load groups. Column (2) introduces fund fixed effects to the specification. Column (3) adds the logarithm of the fund's assets under management in the prior period as a control variable. In general, we find that larger funds tended to have lower net flows over the period of our sample. ${ }^{32}$ Column (4) introduces Month*Year fixed effects to control for time effects. Column (5) introduces an interaction term between the fund's family and the post-reform indicator; this controls for potentially differential trends across fund families over time in the way suggested by Gormley and Matsa (2012).

In Column (6) we control for the past performance of the fund using the Lag Ranked Returns Low and Lag Ranked Returns High variables defined earlier. The sample size in this column is lower in this column because we require six months of lagged return to form the fund ranking variables. Similar to previous studies, we find evidence for a convex performance-flow relationship. The slope in the low performance range (i.e. the coefficient on the Lag Ranked Returns Low variable) is estimated to be negative and statistically insignificant. The coefficient on the Lag Ranked Returns High variable is estimated to be positive and significant, which is consistent with the standard finding in the literature of a convex performance flow relationship (Sirri and Tufano (1998)). In terms of economic magnitude, a 10 percentage point increase in a fund's ranking above the median ranking is associated with a 40 basis point increase in net flows in the current month.

The difference between the high and low entry load funds after the entry load ban, as measured by the coefficient on the Post*High Entry Load Fund variable is estimated as positive across all of these specifications (although not statistically significant except in Columns (1)). While the coefficient of .67 percentage points in the full specification (Column (6)) is not statistically significant at the 5 percent level, the lower bound on the 95 percent confidence interval around this estimate (-.19 percentage points) effectively rules out the possibility of a large negative impact of the reform on net flows. For example, this lower bound on the confidence interval is small in absolute value terms relative to the standard deviation in monthly net flows of 7.19 percentage points in this sample.

Table 6 presents the same specifications as 5 , however we now remove the income funds from the low entry load group. The removal of the income type funds leads to an even larger, positive, and significant estimated difference between the high and low entry load funds in the period after the

\footnotetext{
${ }^{32}$ Using U.S. data on mutual fund flows, Christoffersen et al. (2012) also finds a negative relationship between the logarithm of fund size and inflows.
} 
policy. In these specifications flows in to the high entry load funds were approximately 4 percentage points higher, per month, in the period after the entry load ban versus the period before the entry load ban. Again, these results are inconsistent with the idea that the entry load ban caused lower net flows in to Indian mutual funds. ${ }^{33}$

Overall, our results on asset growth suggest that it is very unlikely that the policy had a causal impact in reducing the net flows in to high entry load funds. If anything, these results suggest that the period after the policy change was a time when previously high entry load funds attracted greater net flows. In fact, we find that as we tighten the comparison between the high and entry load groups (i.e. add more controls in Tables 3, 4, 5, 6), the coefficient on the Post*High Entry Load Group variable tends to increase. While there were important differences between the high and low entry load groups prior to the reform, the fact that controlling for many of these differences leads us to find that the policy had, if anything, a positive impact on flows in to high entry load funds strongly contradicts the idea that this policy has played an important role in the slowdown in mutual fund growth in the post-reform period.

We, however, are cautious to interpret the positive coefficient $\beta_{1}$ estimated here as a direct result of the policy; some additional insight can be gained from interpreting the regression results in light of Figure 9. The estimated positive impact of the policy is primarily driven by a decline in net flows to funds that charged low entry loads in the pre-period, as opposed to an increase in the net flows in to high entry load funds. If the entry load ban policy caused an increase in net flows in to high entry load funds, then we would have expected to see net flows in to high entry load funds rise after the policy change. Instead, we observe that the trend in net flows in the high entry load group has not changed substantially after the reform, while net flows in to the low entry load group have fallen substantially. We suspect that factors independent of the entry load ban, such as different responses of the types of investors that invested in high versus low entry load funds to the financial crisis, may explain these results, although we cannot test this directly.

\subsection{Index Fund Results}

The above results showed that funds that charged high entry loads have not fared especially poorly, in terms of asset growth, relative to funds that charged low entry loads prior to the entry load ban. One potential concern with these results is that entry load levels prior to the reform were not randomly assigned, and therefore there might be other time varying factors correlated with prereform entry loads and unrelated to the reform that mask the true effect of the entry load ban. One fact that makes us less concerned about this is that the pre-reform trends in assets under management and net flows (Figures 8 and 9) in the high and low entry load groups were similar

\footnotetext{
${ }^{33}$ The right panel of Figure 9 shows the time series pattern of net flows in the high and low entry load groups. The figure shows a very similar pattern to the sample where income funds were included.
} 
prior to the reform; it seems reasonable to assume that their trends would have been similar had the reform not occurred.

Nonetheless, in this section we look at a specific set of funds, index funds, where it is unlikely that there were important differences across high and low entry load versions prior to the reform. We compare the asset growth of index funds that charged high entry loads versus those that charged low entry loads, to see if high entry load funds have experienced lower asset growth in the period after the reform. We point out two major differences in our analysis of index funds versus all funds. First, index funds were substantially more likely to charge zero entry loads prior to the reform, and less likely to charge an entry load of $2.25 \%$. Thus, we define our low entry load group for index funds as the group of funds that charged zero percent entry loads prior to the reform, and our high entry load group has the set of funds that charge an entry load greater than zero percent prior to the entry load ban. Second, the sample of index funds in both the high and low entry load groups is relatively small. Thus, the results are more sensitive to the entry and exit of particular funds over time. We discuss this issue further below.

In the appendix we present figures showing the average level of entry loads charged by the high and low entry load index fund group. The figure shows that the high entry load index funds charged approximately 1.3 percent entry loads prior to the reform. The Appendix also contains a figure to show the raw (before fees) returns on index funds. Given that the index funds primarily target one of the two major Indian stock market indices, the raw returns in both of these groups are essentially identical.

Figure 10 presents the average log assets under management for the high and low entry load groups. The left panel includes all index funds in the data. The trends in assets under management across the two groups here are less similar than the corresponding pictures in the sample of all funds; in particular the low entry load group experienced a much larger decline in assets under management during 2008 and early 2009. After the policy change, the high entry load group has experienced a small decline, while the low entry load group has experienced a small increase in assets under management. At the time of policy change there were 18 index funds in each of the high and low entry load index fund groups; these small sample sizes make this comparison vulnerable to the entry and exit of even a small number of funds over time. ${ }^{34}$

To get a better sense of how the entry load policy directly affected funds, the right panel of Figure 10 only includes funds that were in continuous existence for a two year window around the policy change. This figure shows the two groups to be much more similar prior to the policy change. The balanced sample in the right panel includes 34 funds (18 index funds in the high entry load group, and 16 index funds in the low entry load group). In the post-reform period, the high entry load

\footnotetext{
${ }^{34}$ Seven index funds exited in the high entry load index fund group in early 2008 , and 6 index funds entered the low entry load group in the pre-reform period.
} 
funds appear to have perhaps slightly lower asset growth, although it is difficult to determine from the figure alone whether the trends are significantly different. In Tables 7 and 8 we present the estimates of equation (1) on the sample of index funds, unbalanced and balanced respectively, and find that there are no significant differences in the asset growth across the high and low entry load samples of index funds.

Figure 11 presents the average net flows in to high and low index funds. Again, the left panel presents the averages including all funds (even those that entered and/or exited during the sample period). From this figure, it does appear that high entry load funds have experienced lower net flows in the period after the entry load ban relative to low entry load funds. Given the noisiness of these series, however, it is difficult to determine from the figure alone whether these differences are statistically significant. Table 9 conducts an empirical test to determine whether the difference in net flows in to high versus low entry load funds in the post-reform period is significant. The empirical results suggest that these two types of funds did not have significantly different net flows after the policy change, either in a raw comparison (Column (1)), or a specification that includes fund fixed effects, lagged performance, month and year fixed effects, and family fixed effects (Column (6)). None of the specifications in this Table show a significant negative effect of the policy on net flows in to the high entry load index funds.

The right panel of Figure 11 restricts the analysis to funds that were in existence continuously throughout a two year window around the policy change. ${ }^{35}$ This figure shows the two types of funds to have nearly identical net flows around the policy change. Focusing on this balanced sample, the net flows of these two types of funds are quite similar. The empirical results in Table 10 confirm that, within this balanced sample, there is also no significant difference between the net flows of the high and low index fund groups.

\subsection{Changes in Exit Loads Charged by Mutual Funds}

After the entry load ban, Indian mutual funds were allowed to charge two types of fees to meet their marketing and distribution expenses. ${ }^{36}$ So far we have focused on entry loads, which were the primary way funds raised revenues to pay broker commissions. Funds were also allowed to charge exit loads to meet their distribution expenses. Exit loads are fees that are charged to the investor when he removes his money from the fund. One possibility is that Indian mutual funds raised exit loads in response to the entry load ban, as a way to increase their available funding for distribution expenses. 37

\footnotetext{
${ }^{35}$ The net flow in this balanced sample is only available for 6 funds in the high entry load group and 10 funds in the low entry load group.

${ }^{36}$ For a general discussion of the economic rationale for different types of mutual fund fees see Chordia (1996).

${ }^{37}$ Indian mutual funds also charge management fees as a percentage fee of the total amount of money invested in the fund over a year (these fees are pro-rated for partial year investments). However, up until August of 2012 Indian
} 
The entry load ban policy change explicitly allowed funds to charge up to one percent in exit loads and use revenues from those exit loads to pay commissions to brokers who sold mutual fund products. We now present evidence on whether funds increased exit loads after the imposition of the entry load ban. Our primary source of data on exit loads comes from the monthly mutual fund factsheets that Indian fund companies are required to post on their websites. Exit loads are typically only charged to an investor if they exit the fund within a pre-specified period of time after the their investment. For example, many funds charge investors one percent of the amount withdrawn if the money is withdrawn within the first year. Some funds charged a schedule of exit loads, i.e. one percent if you exit in less than 180 days and .5 percent if you exit between 180 and 365 days.

In general, firms had two levers to increase revenues from exit loads after the ban on entry loads was introduced. First, they could increase the percentage rate charged to investors upon exit. Second, they could increase the time period that exit loads were applied to (for example requiring a one percent exit load if investors exited within the first two years, as opposed to just the first year). To quantify changes in both of these types of fees we calculate the following three measures of exit loads for each fund*month observation: the exit load charged for exiting in the first thirty days after investment $\left(x_{1}\right)$, the exit load charged for exiting between 30 and 180 days after investment $\left(x_{2}\right)$, and the exit load charged for exiting between 180 and 365 days $\left(x_{3}\right) .{ }^{38}$ We chose these cut-off points to correspond to the most common cut-off points of exit loads in our data.

As an example, consider a fund that charged a 1 percent exit load for exiting within 30 days after investment, a .5 percent exit load for exiting between 30 days and 180 days after investment, and a .25 percent exit load for exiting between 180 and 365 days after investment. This fund would have $x_{1}=1, x_{2}=.5, x_{3}=.25$. We make separate plots for each $x_{i=\{1,3\}}$ in the high entry load versus low entry load group, to assess whether exit loads were differentially increased more in high entry load funds as a way to raise revenue to pay commissions. ${ }^{39}$

Figures 12, 13, and 14 present the average exit load charged by funds in the high entry load and low entry load groups separately for the measures $x_{1}, x_{2}$ and $x_{3}$ respectively. The left panel in each of these figures includes the full sample of funds where were able to obtain exit load data, and therefore represent both changes of exit loads within funds, as well as the changes in the composition of the sample due to availability of the exit load data. The left panels begin in April 2007 as prior to this we were only able to obtain exit load data for less than 10 funds in the low entry load group.

mutual funds were not allowed to use funds raised as management fees for marketing and distribution purposes, so it was not possible for funds to adjust management fees as a way to increase revenues to pay for marketing expenses.

${ }^{38}$ Less than five percent of funds charged any exit load for exit after 365 days, so we do not include data on fees charged for longer than 365 days.

${ }^{39}$ In the case where a fund had a cut-off in-between our chosen cut-offs of 30, 180, and 365 days we calculated the average fee within our cutoffs weighted by the number of days the fee was applicable. For example, a fund that charged 1 percent if you the investor exited within 25 days, and zero for exit after 25 days, would have $x_{1}=\frac{25}{30} 1+\frac{5}{30} 0=\frac{5}{6}$. 
Starting in April 2007 we have exit load data on at least 16 funds in the low entry load group. The right panel in each of the figures presents the average exit load for the sample of funds in the high and low entry load groups where we found exit load data for every month during the period one year before and one year after the policy change. The right panels therefore give a better sense of how individual funds changed their exit loads in response to the policy change.

We point out two important results from these figures. First, all of the figures show that in general exit loads at any point in time were higher for funds in the high entry load group versus the low entry load group. This is consistent with the idea that funds that charged high entry loads also tended to charge high exit loads.

Second, focusing on the left panel within each of these figures, in the high entry load group there has been a steady increase in exit loads over time, but there appears to be no discrete changes in exit loads charged at the time of the reform. In the low entry load group, exit loads have also increased slowly over time. There is a discernable increase in exit loads in the low entry load group around six months prior to the reform. However, this jump is primarily driven by the entry of some new funds at around this time that charged higher exit loads. Looking at the right panel of each of these figures, which focuses on the set of funds that existed throughout a two year window around the policy change, neither the high or low entry load group show any meaningful changes around

the policy change. Overall, these figures suggest that mutual fund companies did not increase exit loads as a way to increase revenues to pay commissions once the entry load ban was put in place.

We also obtained data from Karvy Computershare Ltd., one of the two large technology firms that handles the intermediation process between brokers and mutual fund companies. Karvy intermediates approximately 45 percent of the total flows in to Indian mutual funds. Karvy provided us with aggregate data on the amount of exit loads collected as well as the total amount of outflows, per month, for Indian non-index equity mutual funds. We can use this data to calculate the effective exit load rate paid by investors. Figure 15 shows the amount of revenues generated through exit loads by mutual funds. This figure shows that the policy change did not substantially effect the amount of exit loads collected by funds, either in terms of the percentage rate charged, or in terms of the absolute amount of exit loads charged.

\section{Where Did Households Invest?}

The results so far are inconsistent with the entry-load ban being the main reason for the massive outflows out of mutual funds after the entry load ban. What then explains the outflows observed in the Indian mutual funds industry during the post entry load ban period?

The period between 2009 and 2012 followed the 2008 financial crisis and was also characterized by 
very high rates of inflation. This perhaps made households wary of investing in financial assets, and led them towards real assets such as housing and gold. ${ }^{40}$ We suspect that this general pattern is responsible for the aggregate decline in net flows in to mutual funds during this period, as opposed to the ban on entry loads.

Aggregate data from the Reserve Bank of India suggests that the period after the entry load ban was in general a time when households were moving out of financial assets and in to real assets such as gold and real estate. Net financial saving (i.e. savings in financial instruments such as stocks, mutual funds, bonds, and bank accounts) fell from 12.2 percent of GDP in financial year 2009-2010 to 9.3 percent in 2010-2011, and to 7.8 percent in 2011-2012 (Reserve Bank of India, 2012). The 2011-2012 Annual Report of the Reserve Bank of India highlights this issue specifically:

...with real interest rates on bank deposits and instruments such as small savings remaining relatively low on account of the persistent high inflation, and the stock market adversely impacted by global developments, households seemed to have favoured investment in valuables, such as gold. In the post-global crisis period, valuables have increased from 1.3 per cent of GDP at current market prices in 2008-09 to 2.8 per cent in 2011-12; the share of valuables in investment (gross capital formation) has also increased from 3.7 per cent to 7.9 per cent, over this period. The apparent proclivity of households towards investment in valuables such as gold could have also impacted the pace of their investment in physical assets such as housing in 2011-12.

To confirm that the above aggregate patterns are also likely to be true for household investments in to mutual funds we use data from Consumer Pyramids, a newly available representative household survey of all households in India conducted by the Centre for Monitoring Indian Economy (CMIE) on a quarterly basis. This is a panel data set where each survey household is contacted quarterly to answer questions on income, consumption, saving and borrowing. This survey began in March of 2009 with 120,000 households. In March 2011, new households were added to the panel and the sample size was increased to 150,000 households. ${ }^{41}$

In Figure 16 we present the proportion of households with outstanding investments in various asset classes. This includes financial instruments such as mutual funds, life insurance, and fixed deposits as well as real assets such as gold and real estate. The figure shows a substantial increase in the proportion of total households with outstanding investments in gold and real-estate.

\footnotetext{
${ }^{40}$ For research on gold as an inflation hedge, see Ghosh et al. (2004). For research on the effectiveness of real estate as an inflation hedge see Rubens et al. (2009).

${ }^{41}$ A household in the Consumer Pyramids data includes persons who share a "common kitchen". Multiple levels of geographical stratification were followed by the random selection of villages and Census Enumeration Blocks (CEBs) ${ }^{42}$ from cities.
} 


\section{Conclusion}

We study the impact of a ban on entry-loads which reduced the ability of Indian mutual funds to pay commissions to financial product brokers. Aggregate data shows that net flows in to mutual funds declined dramatically in the three years after the entry load ban was introduced.

We expect that if entry load ban led to increased search costs for customers as brokers were no longer interested in selling products, fund growth should be lower for previously high entry load funds relative to low entry load funds. We find evidence to the contrary. When we analyze the simplest measure of fund size, assets under management, that, if anything, previously high entry load funds have experienced less of a decline in assets under management than low entry load funds. Our analysis of net flows finds similar results.

Our study provides new evidence on how regulations aimed at capping broker compensation change overall mutual fund flows. Unfortunately, data limitations prevent us from doing a complete welfare analysis of this policy change. For example, it is possible that the policy has had large benefits by reducing how much investors churn their investments, as brokers no longer have an incentive to encourage investors to enter and exit funds frequently to maximize entry load earnings. Currently available data do not allow us to estimate how the policy has affected investment churning, as this would required high frequency investor level data on the purchase and sale of mutual fund products which is currently not available in the Indian context.

It is also important to note that our results are specific to the market conditions experienced in India after the post 2009 entry load ban. As we have shown, it appears to have been a time when investors primarily moved assets from financial assets to real assets. It is possible that our results might have been different if the entry load ban had been initiated during a time when investors were still eager to invest in financial assets. More research is needed to understand how the impact of direct interventions in the sales processes of financial products interact with market conditions. 


\section{References}

Anagol, Santosh and Hoikwang Kim, "The Impact of Shrouded Fees: Evidence from a Natural Experiment in the Indian Mutual Funds Market," American Economic Review, 2012, 102 (1), 576-593.

_ , Shawn Cole, and Shayak Sarkar, "Understanding the Incentives of Commissions Motivated Agents: Theory and Evidence from the Indian Life Insurance Market," Working Paper, 2012.

Barber, Brad M., Terrance Odean, and Lu Zheng, "Out of Sight, Out of Mind: the Effects of Expenses on Mutual Fund Flows," Journal of Business, 2005, 78 (6), 2095-2119.

Bergstresser, Daniel, John M. R. Chambers, and Peter Tufano, "Assessing the Costs and Benefits of Brokers in the Mutual Fund Industry," The Review of Financial Studies, 2009, 22 (10), 4129-4156.

Bowen, Chris, "Future of Financial Advice: Information Pack," Technical Report, Commonwealth of Australia 2011.

Campbell, John, Howell Jackson, Brigitte Madrian, and Peter Tufano, "Consumer Financial Protection," Journal of Economic Perspectives, 2011, 25(1), 91-114.

Carlin, Bruce and David Robinson, "What Does Financial Literacy Training Teach Us?," Working Paper, 2011.

Chanda, D., "Re: Rationalisation of Initial Issue Expenses and Dividend Distribution Procedure for Mutual Funds," Circular, Securities and Exchange Board of India 2006.

Chordia, Tarun, "The Structure of Mutual Fund Charges," Journal of Financial Economics, 1996, 41 (1), 3-39.

Christoffersen, Susan, Richard Evans, and David Musto, "What Do Consumers' Fund Flows Maximize? Evidence from Their Brokers' Incentives," Journal of Finance, 2012, forthcoming.

Cole, Shawn and Gauri Kartini Shastry, "Smart Money: The Effect of Education, Cognitive Ability, and Financial Literacy on Financial Market Participation," Working Paper 2010.

_ , Thomas Sampson, and Bilal Zia, "Prices or Knowledge? What Drives Demand for Financial Services in Emerging Markets?," Journal of Finance, 2011, forthcoming.

Ferris, Stephen and Don Chance, "The Effect of 12b-1 Plans on Mutual Fund Expense Ratios: A Note," Journal of Finance, 1987, 42 (4), 1077-1982. 
_ and _ , "Mutual Fund Distribution Fees: An Empirical Analysis of the Impact of Deregulation," Journal of Financial Services Research, 1991, 5, 25-42.

Friend, Irwin, Francis Brown, Edward Herman, and Douglas Vickers, "A Study of Mutual Funds," Technical Report, U.S. Government Printing Office 1962.

Gabaix, Xavier and David Laibson, "Shrouded Attributes, Consumer Myopia, and Information Suppression in Competitive Markets," Quarterly Journal of Economics, 2006, 121 (2), 505-540.

Ghosh, Dipak, Eric Levin, Peter MacMillan, and Robert Wright, "Gold as an Inflation Hedge?," Studies in Economics and Finance, 2004, 22 (1), 1-25.

Gormley, Todd and David Matsa, "Common Errors: How to (and Not to) Control for Unobserved Heterogeneity," Working Paper, 2012.

Halan, Monika, "Mint 50: Mutual Funds to Invest In," Livemint, 2010.

Hastings, Justine and Olivia Mitchell, "How Financial Literacy and Impatience Shape Retirement Wealth and Investment Behaviors," Working Paper, NBER January 2011.

_, Brigitte Madrian, and William Skimmyhorn, "Financial Literacy, Financial Education, and Economic Outcomes," NBER Working Paper, 2012.

Hortacsu, Ali and Chad Syverson, "Product Differentiation, Search Costs, and Competition in the Mutual Fund Industry: A Case Study of S\&P 500 Index Funds," Quarterly Journal of Economics, 2004, 119 (2), 403-456.

Jia, Panle and Parag Pathak, "The Impact of Commissions on Home Sales in Greater Boston," American Economic Review, 2009, Papers and Proceedings.

Kamiyama, Tetsuya, "India's Mutual Fund Industry," 2007, 10 (4).

Ko, Jeremy K. and Alex Yoon-Ho Lee, "Economic Models and Regulatory Remedies for the Problem of Consumer Credit," Available at SSRN: http://ssrn.com/abstract=1800848 August 2011.

Koszegi, Botond, Paul Heidhues, and Takeshi Murooka, "The Market for Deceptive Products," Working Paper, 2012.

Levitt, Steve and Chad Syverson, "Market Distortions when Agents are Better Informed: The Value of Information in Real Estate Transactions," Review of Economics and Statistics, 2008, 90 (4), 599-611.

Mullainathan, Sendhil, Markus Noeth, and Antoinette Schoar, "The Market for Financial Advice: An Audit Study," NBER Working Paper, 2012. 
Ottaviani, Marco and Roman Inderst, "How (Not) to Pay for Advice: A Framework for Consumer Financial Protection," Working Paper, 2011, forthcoming.

Reserve Bank of India, "Reserve Bank of India Annual Report," Technical Report 2012.

Rubens, Jack, Michael Bond, and James Webb, "The Inflation-Hedging Effectiveness of Real Estate," Journal of Real Estate Research, 2009, 4 (2), 45-55.

Securities and Exchange Board of India, "Waiver of load for direct applications," Technical Report, Securities and Exchange Board of India 2007.

_ , "The Gazette of India: Extraordinary Part - III - Section 4," Technical Report, Securities and Exchange Board of India 2012.

_ , "Master Circular for Mutual Funds," Circular, Securities and Exchange Board of India 2012.

Shah, Alpesh, Ashish Garg, Kamala Radhakrishnan, and N.K. Prasad, "Equity Mutual Funds: Charting Your Course with a Compass," Boston Consulting Group, 2010.

Shah, Mehul and Chandan Kant, "Top distributors make millions as fund houses bleed," http://business-standard.com/india/news/ top-distributors-make-millions-as-fund-houses-bleed/470840/ April 11, 2011.

Sirri, E. and P. Tufano, "Costly Search and Mutual Fund Flows," Journal of Finance, 1998, 53, $1589-1622$.

Trzcinka, Charles and Robert Zweig, "An Economic Analysis of the Cost and Benefits of SEC Rule 12b-1," Monograph Series in Finance and Economics, Salomon Brothers Center for the Study of Financial Institutions 1990.

Walsh, Lori, "The Costs and Benefits to Fund Shareholders of 12b-1 Plans: An Examination of Fund Flows, Expenses and Returns," Working Paper, Securities and Exchange Commission 2005.

Zhao, Xinge, "Conflict of Interests Between Load Fund Investors and Brokers and Financial Advisors," Working Paper, 2008. 


\section{Figure 1 Net Flows into Equity Open Ended Mutual Funds}

This figure presents the net flows into Equity Open Ended mutual funds on the left hand side y-axis in crores of rupees (1 Crore Rupees equals approximately 200,000 U.S.D). The level of the Bombay Sensex Index (Indian stock market index) is shown as a sold line and is measured on the right hand side y-axis. The dashed vertical line indicates the policy change that eliminated the ability of mutual funds to charge entry loads.

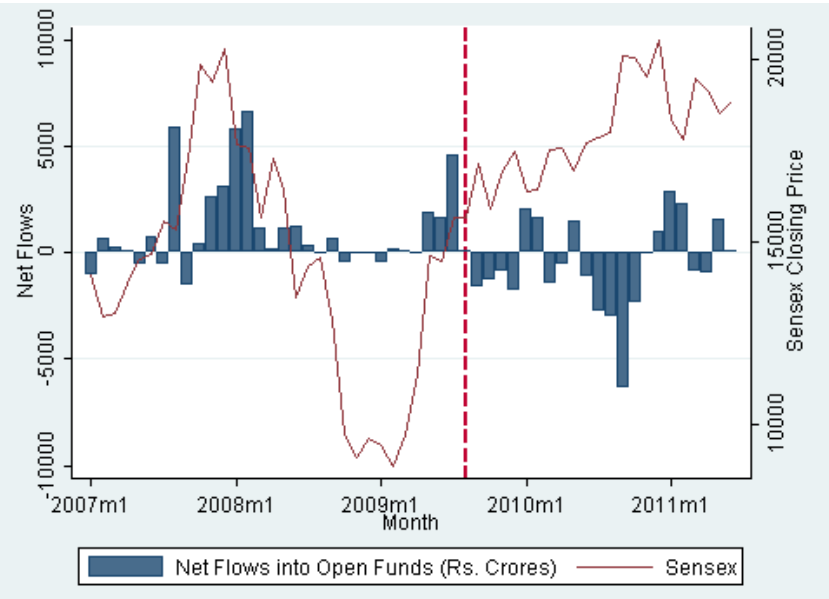

\section{Figure 2 Inflows To and Outflows From Equity Open Ended Mutual Funds}

This left panel in this figure presents the gross inflows into Equity Open Ended mutual funds in crores of rupees (1 Crore Rupees equals approximately 200,000 U.S.D). The right panel shows the gross outflows out of Equity Open Ended mutual funds in crores of rupees. The level of the Bombay Sensex Index (Indian stock market index) is shown as a sold line and is measured on the right hand side $y$-axis in both panels. The dashed vertical line indicates the policy change that eliminated the ability of mutual funds to charge entry loads.

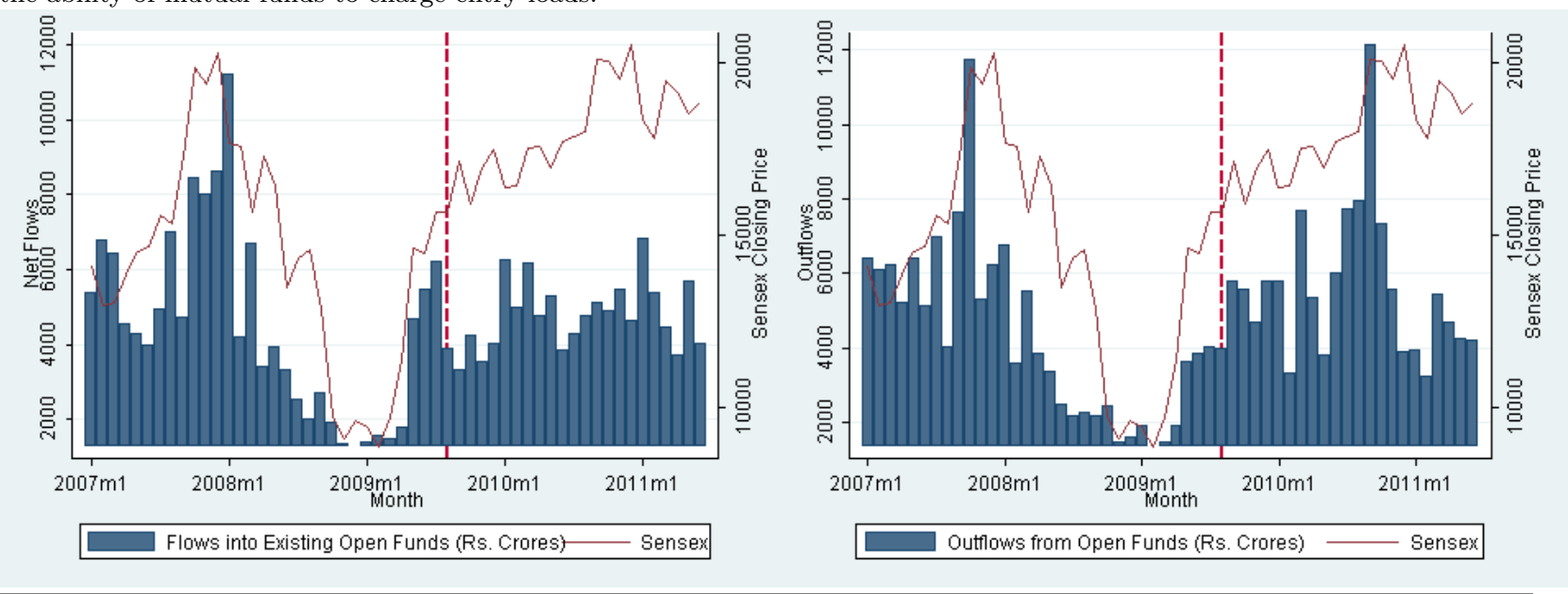


Figure 3 Aggregate Number of Investor Accounts

This figure shows the total number of retail investor mutual fund accounts in the Indian mutual funds market.

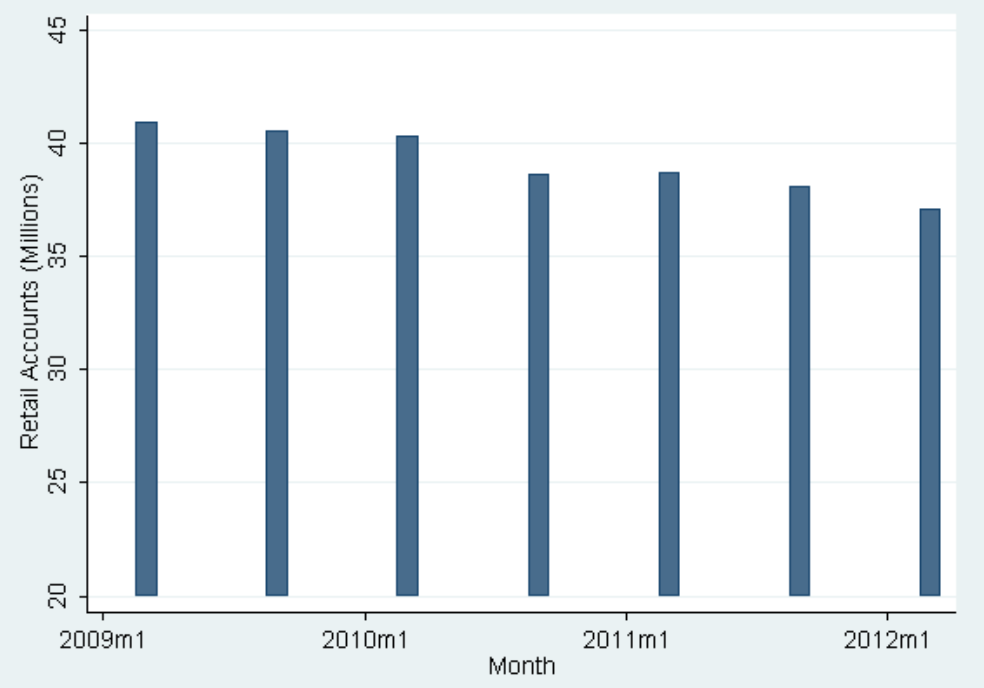

Figure 4 Histogram of Net Flows Data after Trimming

This figure presents a histogram of monthly net-flows in the full sample of data we analyze. The bottom and top 1 percent of observations in terms of net-flows have been removed to eliminate major outliers.

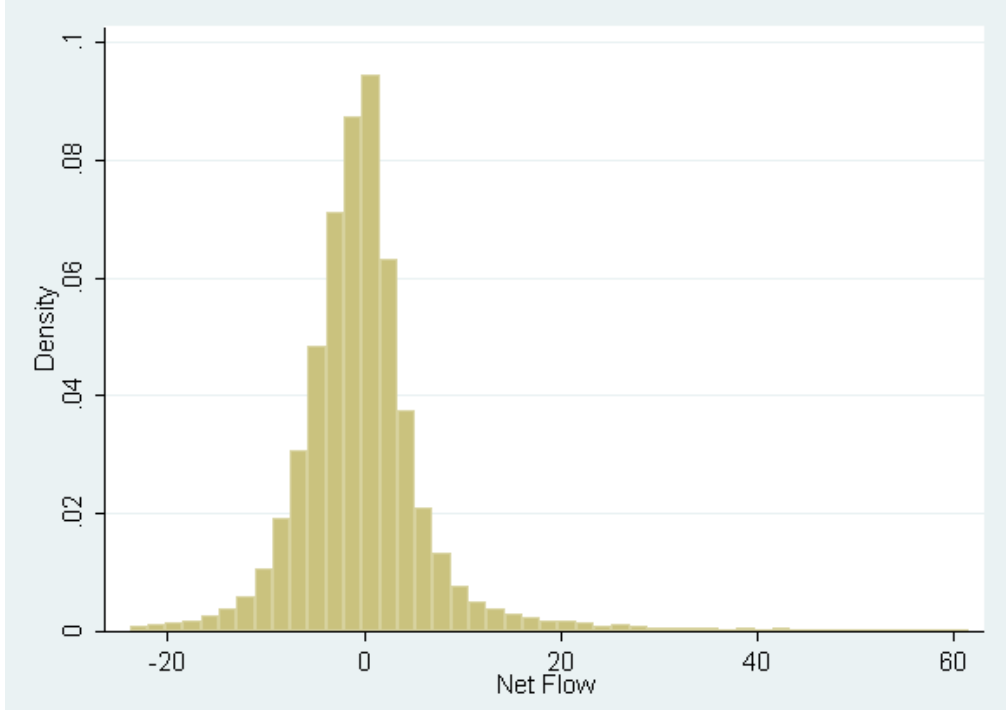




\section{Figure 5 Distribution of Fund Observations Across Entry Load Levels}

This figure presents a histogram of monthly fund observations across the levels of entry loads charged in the pre-reform sample (all entry loads were mandated to be equal to zero in the post-reform sample). The two major mass points are at entry loads equal to 0 percent and entry loads equal to 2.25 percent.

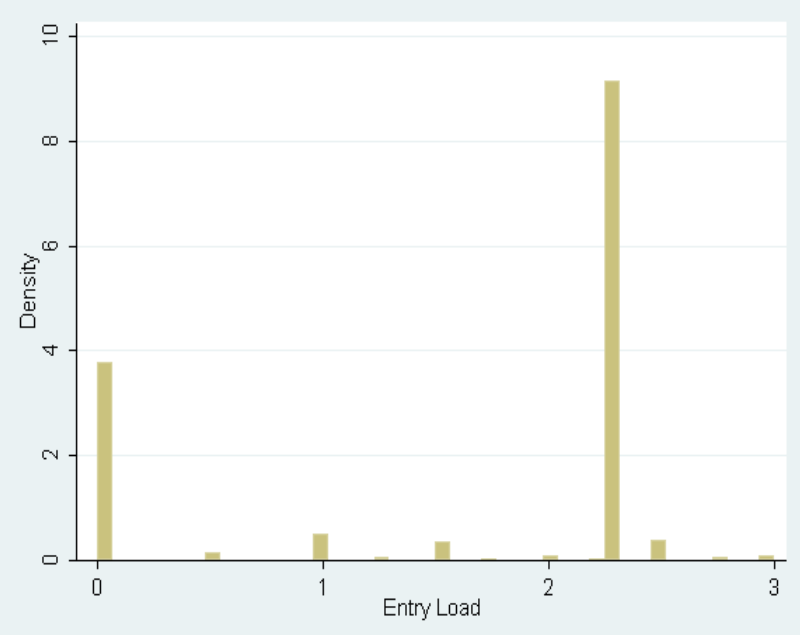

\section{Figure 6 Entry Loads on High Vs. Low Fee Funds}

This figure shows the average entry loads charged by funds in the high entry load fund group and the low entry load fund group. The high entry load group is defined as any fund that charged an entry load of 2.25 percent or higher prior to the reform; the low entry load group is the set of funds that charged entry loads less than 2.25 percent prior to the reform. The dashed vertical line indicates the date the policy went in to force (August 2009). The left panel includes all funds. The right panel excludes funds that invested only a small portion of their portfolios in equity.
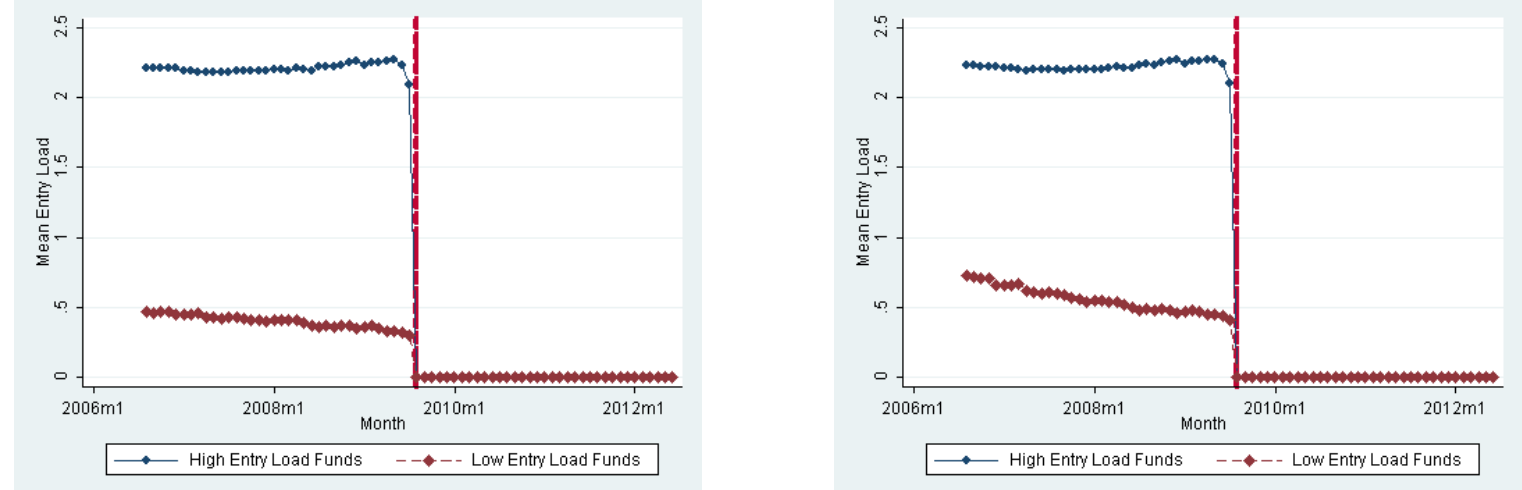


\section{Figure 7 Returns on High Vs. Low Fee Funds}

This figure shows the average returns earned in the high and low entry load groups over time.. The left and right y-axis scales refer to the mean returns in to the high and low entry load groups respectively. The high entry load group is defined as any fund that charged an entry load of 2.25 percent or higher prior to the reform; the low entry load group is the set of funds that charged entry loads less than 2.25 percent prior to the reform. The left-axis is the scale for high entry load funds, and the right axis is the scale for low entry load funds. The dashed vertical line indicates the date the policy went in to force (August 2009). The left panel includes all funds. The right panel excludes funds that invested only a small portion of their portfolios in equity.
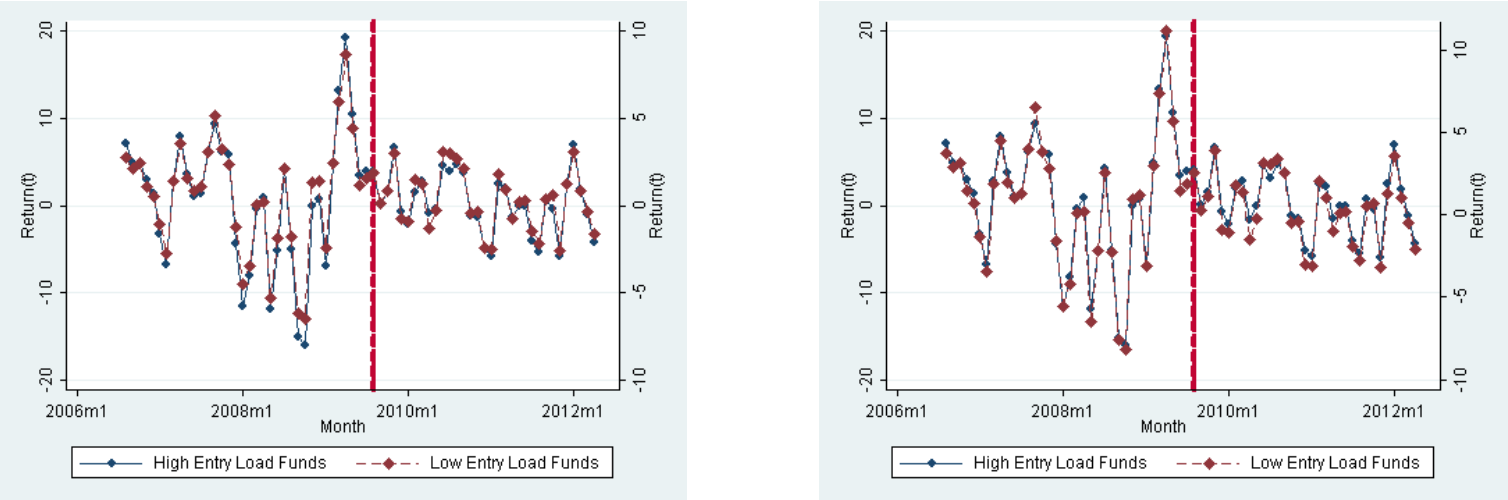

\section{Figure 8 Assets Under Management in High Vs. Low Fee Funds}

This figure presents the logarithm of the assets under management in the high entry load group (solid line) and the low entry load group (dashed line). The high entry load group is defined as any fund that charged an entry load of 2.25 percent or higher prior to the reform; the low entry load group is the set of funds that charged entry loads less than 2.25 percent prior to the reform. The left-axis is the scale for high entry load funds, and the right axis is the scale for low entry load funds. The dashed vertical line indicates the date the policy went in to force (August 2009). The left panel includes all funds. The right panel excludes funds that invested only a small portion of their portfolios in equity.
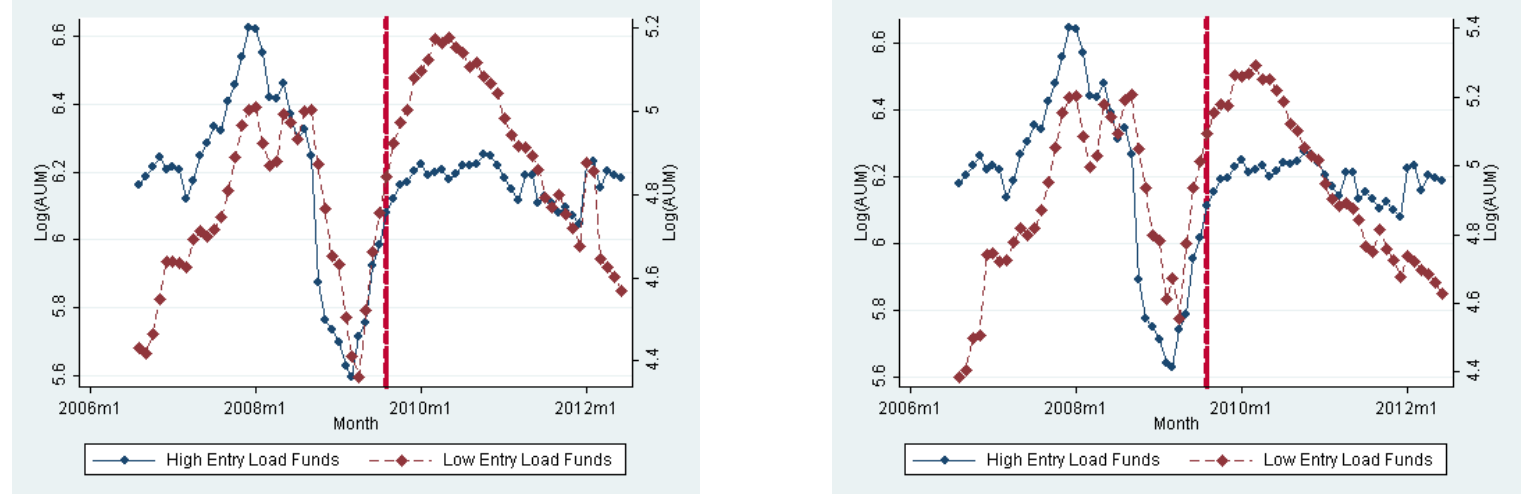


\section{Figure 9 Average Net Flows in High Vs. Low Fee Funds}

This figure presents the average net-flows in to funds in the high entry load group (solid line) and the low entry load group (dashed line). The underlying data were trimmed to remove the top and bottom one percent of net-flow observations. The high entry load group is defined as any fund that charged an entry load of 2.25 percent or higher prior to the reform; the low entry load group is the set of funds that charged entry loads less than 2.25 percent prior to the reform. The left-axis is the scale for high entry load funds, and the right axis is the scale for low entry load funds. The dashed vertical line indicates the date the policy went in to force (August 2009). The left panel includes all funds, and the right panel excludes income type funds.
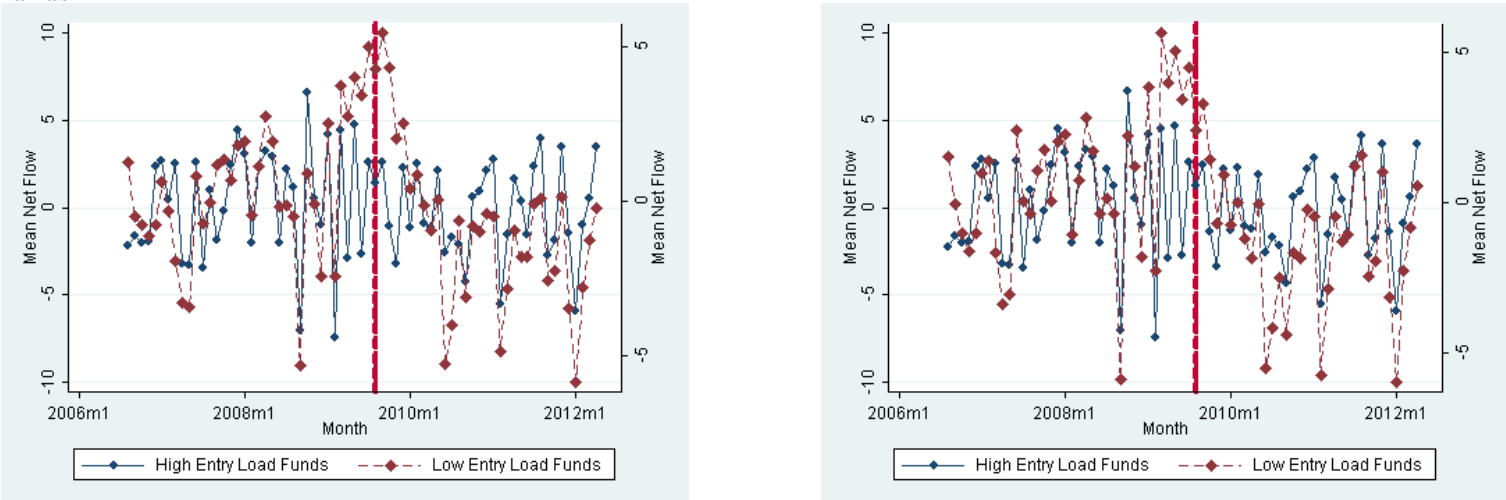

Figure 10 Index Funds: Assets Under Management in High Vs. Low Fee Funds

This figure presents the logarithm of assets under management in the high entry load index fund group (solid line) and the low entry load index fund group (dashed line). The high entry load group is defined as any fund that charged an entry load greater than zero prior to the reform; the low entry load group is the set of funds that charged zero entry loads prior to the reform. The left-axis is the scale for high entry load funds, and the right axis is the scale for low entry load funds. The dashed vertical line indicates the date the policy went in to force (August 2009). The sample in the right panel is restricted to funds where we observed assets under management for all of the months within a two year window around the entry load reform.
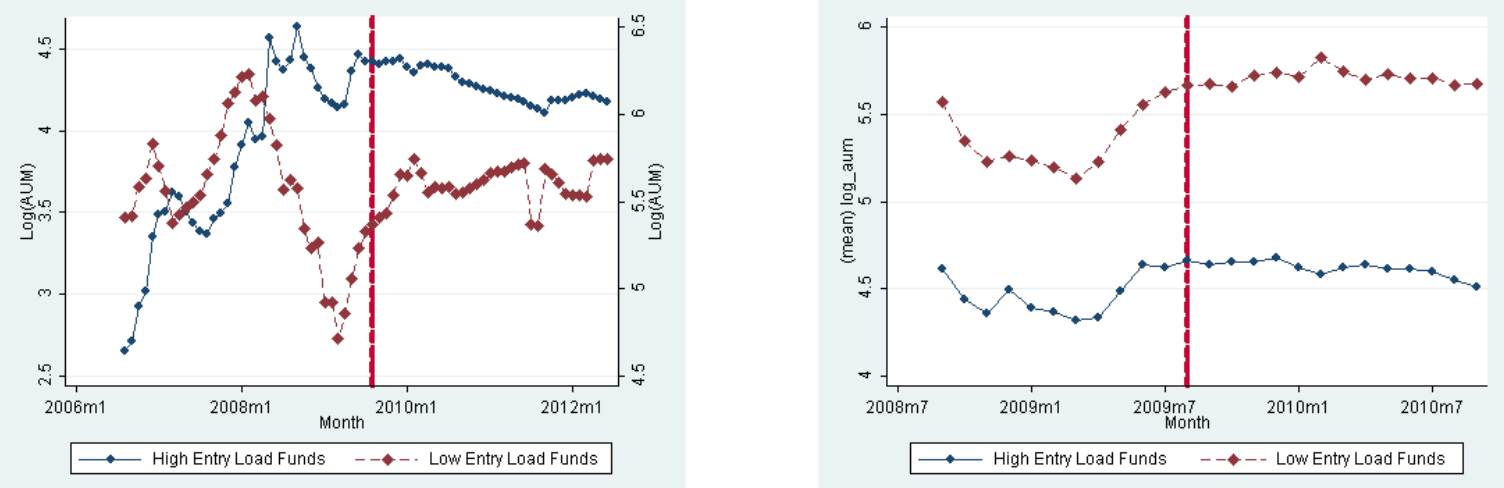


\section{Figure 11 Index Funds: Average Net Flows in High Vs. Low Fee Funds}

This figure presents the average net flows in the high entry load index fund group (solid line) and the low entry load index fund group (dashed line). The high entry load group is defined as any fund that charged an entry load greater than zero prior to the reform; the low entry load group is the set of funds that charged zero entry loads prior to the reform. The left-axis is the scale for high entry load funds, and the right axis is the scale for low entry load funds. The dashed vertical line indicates the date the policy went in to force (August 2009). The sample in the right panel is restricted to funds where we observed net flows for all of the months within a two year window around the entry load reform.
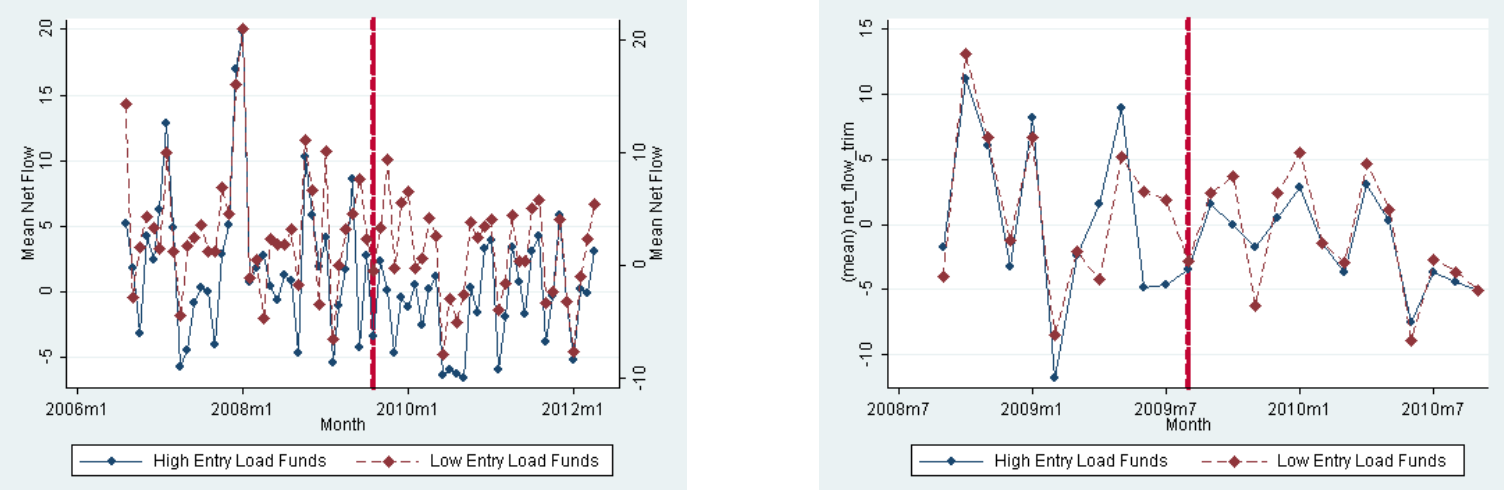

\section{Figure 12 Exit Loads Payable for Exit Within First 30 Days}

This figure presents the average exit load charged by an investor who exited within the first 30 days in funds in the high entry load group (solid line) and the low entry load group (dashed line). The high entry load group is defined as any fund that charged an entry load of 2.25 percent or higher prior to the reform; the low entry load group is the set of funds that charged entry loads less than 2.25 percent prior to the reform. The dashed vertical line indicates the date the policy went in to force (August 2009). The left panel includes all funds in the high and low entry load groups. The right panel includes the sub-sample of funds in each group where we were able to obtain exit load data for all the months within a two year window of the entry load ban.
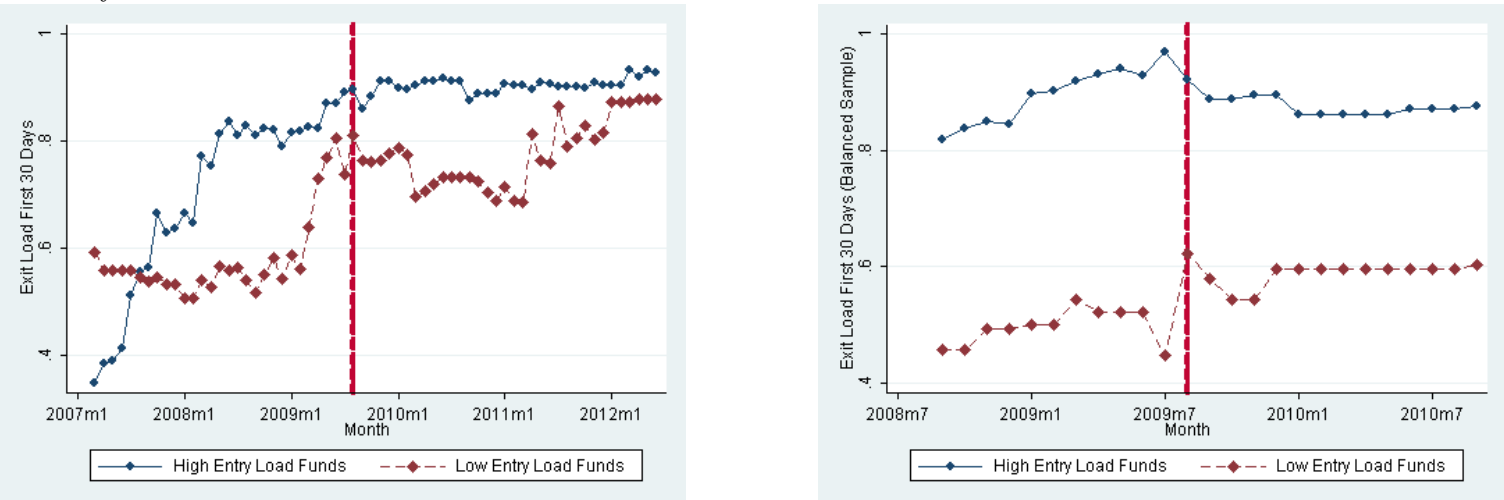


\section{Figure 13 Exit Loads Payable for Exit Between 31 and 180 Days}

This figure presents the average exit load charged by an investor who exited after 30 days but before 180 days in funds in the high entry load group (solid line) and the low entry load group (dashed line). The high entry load group is defined as any fund that charged an entry load of 2.25 percent or higher; the low entry load group is the set of funds that charged entry loads less than 2.25 percent prior to the reform. The dashed vertical line indicates the date the policy went in to force (August 2009). The left panel includes all funds in the high and low entry load groups. The right panel includes the sub-sample of funds in each group where we were able to obtain exit load data for all the months within a two year window of the entry load ban.
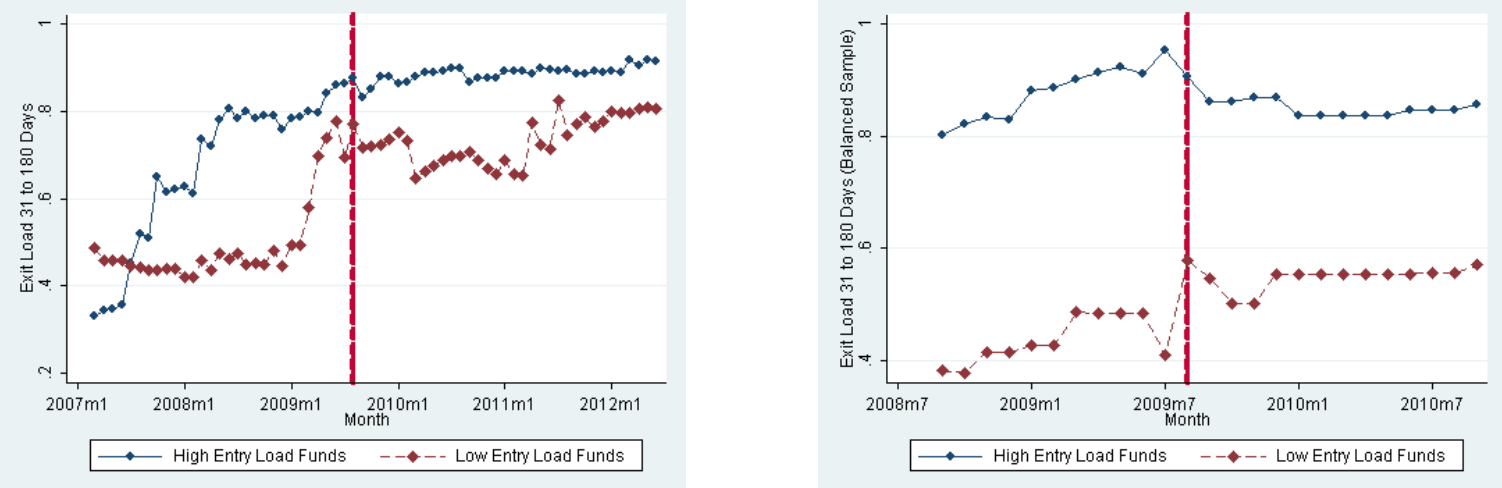

\section{Figure 14 Exit Loads Payable for Exit Between 181 and 365 Days}

This figure presents the average exit load charged by an investor who exited after 181 days but before 365 days in funds in the high entry load group (solid line) and the low entry load group (dashed line). The high entry load group is defined as any fund that charged an entry load of 2.25 percent or higher prior to the reform; the low entry load group is the set of funds that charged zero entry loads less than 2.25 percent prior to the reform. The dashed vertical line indicates the date the policy went in to force (August 2009). The left panel includes all funds in the high and low entry load groups. The right panel includes the sub-sample of funds in each group where we were able to obtain exit load data for all the months within a two year window of the entry load ban.
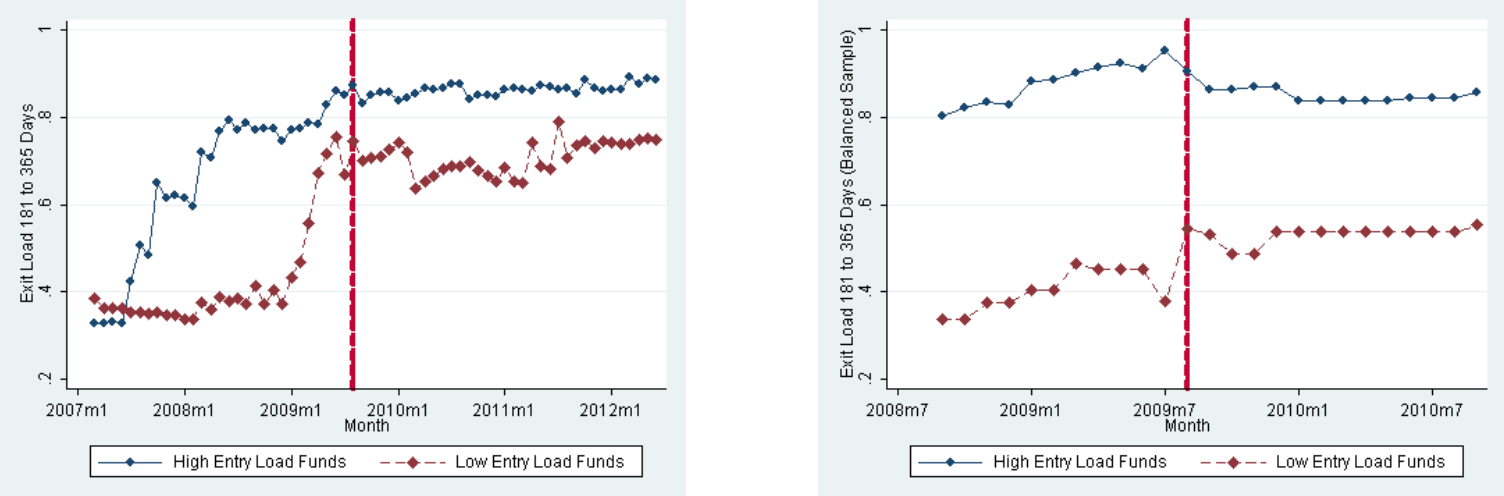


\section{Figure 15 Exit Loads Collected}

This figure presents the exit loads over time. The left panel shows exit loads as a percentage of all fees, and the right panel presents the total amount (in Rs.) of exit loads collected.
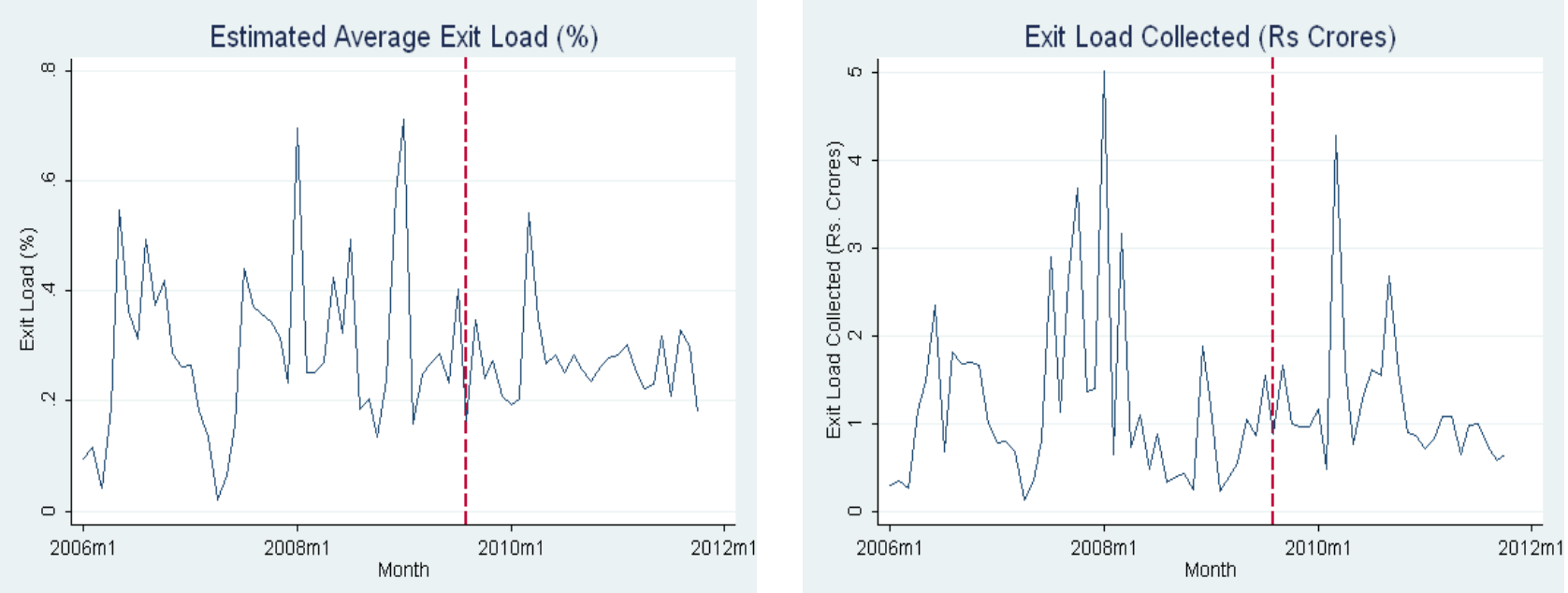

Figure 16 Proportion of Households with Outstanding Investments in Major Asset Classes

This figure presents the proportion of households with outstanding investments in various assets in each quarter.

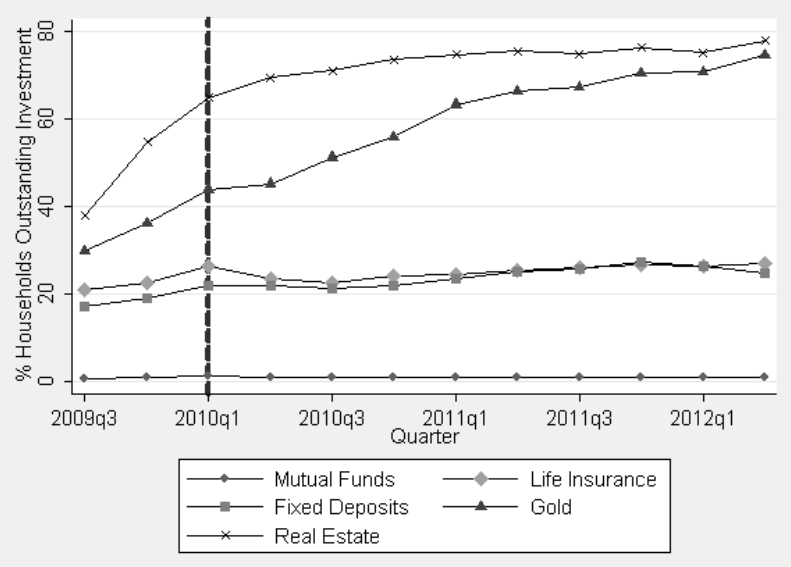


Table 1 Summary Statistics

This table presents summary statistics on low entry load funds, high entry load funds, and all funds. The high entry load group is defined as any fund that charged an entry load of 2.25 percent or higher prior to the reform; the low entry load group is the set of funds that charged entry loads less than 2.25 percent prior to the reform. The Total column includes all funds in the data. Conversions from Indian Rupees to U.S. Dollars are done at 50 rupees per dollar. Standard deviations of the variable are presented in parentheses below the mean. The significance stars in the high entry load funds column indicate whether the mean value of the variable is significantly different across the High and low entry load groups. $* * *, * *, *$ indicate significance at $1 \%, 5 \%, 10 \%$ respectively.

\begin{tabular}{lccc}
\hline \hline & & & \\
& Low Entry Load Group & High Entry Load Group & Total \\
\hline Entry Load (\%) & 0.42 & $2.22^{* * *}$ & 1.76 \\
& $(0.62)$ & $(0.38)$ & $(0.90)$ \\
Net Flow (1\% Trim) & 0.41 & 0.38 & 0.38 \\
& $(9.69)$ & $(7.70)$ & $(8.24)$ \\
Assets Under Management (Rupees Millions) & 1111.5 & $2356.8^{* * *}$ & 2042.4 \\
& $(4864.6)$ & $(4293.9)$ & $(4477.6)$ \\
Assets Under Management (U.S. Dollars Millions) & 22.2 & $47.1^{* * *}$ & 40.8 \\
& $(97.3)$ & $(85.9)$ & $(89.6)$ \\
Log(AUM(t)) & 4.69 & $6.19^{* * *}$ & 5.81 \\
& $(2.38)$ & $(2.30)$ & $(2.41)$ \\
Return(t) (\%) & 0.66 & $0.82^{* * *}$ & 0.78 \\
Management Expense Ratio & $(5.23)$ & $(8.67)$ & $(7.94)$ \\
& 1.06 & $2.09^{* * *}$ & 1.87 \\
Exit Load First 30 Days & $(0.62)$ & $(0.50)$ & $(0.68)$ \\
& 0.44 & $0.70^{* * *}$ & 0.64 \\
Exit Load 31 to 180 Days & $(0.47)$ & $(0.53)$ & $(0.53)$ \\
Exit Load 181 to 365 Days & 0.37 & $0.66^{* * *}$ & 0.60 \\
Minimum Investment (Rupees) & $(0.47)$ & $(0.53)$ & $(0.53)$ \\
Minimum Investment (U.S. Dollars) & 0.33 & $0.65^{* * *}$ & 0.58 \\
& $(0.47)$ & $(0.55)$ & $(0.55)$ \\
\hline \hline Observations & 8016.2 & $\left(445.3^{* * *}\right.$ & 5347.2 \\
& $(6714.0)$ & $(2374.9)$ & $(4226.7)$ \\
& 160.3 & $89.2^{* * *}$ & 106.9 \\
& $(134.3)$ & $(47.5)$ & $(84.5)$ \\
\hline
\end{tabular}




\section{Table 2 Fund Categories by Entry Load Levels Prior to the Reform}

This table presents the proportion of funds in broadly defined categories in the low and high entry load groups. The high entry load group is defined as any fund that charged an entry load of 2.25 percent or higher prior to the reform; the low entry load group is the set of funds that charged entry loads less than 2.25 percent prior to the reform. The Total column includes all funds in the data. The significance stars in the high entry load funds column indicate whether the mean value of the variable is significantly different across the High and low entry load groups. ***,**, indicate significance at $1 \%, 5 \%, 10 \%$ respectively.

\begin{tabular}{lccc}
\hline \hline & & & \\
& Low Entry Load Group & High Entry Load Group & Total \\
\hline Index Fund & 0.15 & $0.022^{* * *}$ & 0.053 \\
Tax Fund & 0.0099 & $0.087^{* * *}$ & 0.068 \\
General Equity Fund & 0.32 & $0.49^{* * *}$ & 0.45 \\
Large Cap Fund & 0.014 & $0.033^{*}$ & 0.028 \\
Sector Fund & 0.035 & $0.17^{* * *}$ & 0.14 \\
Income Fund & 0.31 & $0.0066^{* * *}$ & 0.082 \\
International Fund & 0 & $0.041^{* * *}$ & 0.030 \\
Small and Mid Cap Fund & 0.015 & $0.077^{* * *}$ & 0.061 \\
Balance Fund & 0.14 & $0.066^{* * *}$ & 0.084 \\
Gold Fund & 5776 & 0.0043 & 0.0077 \\
\hline Observations & & & 22819 \\
\hline \hline
\end{tabular}




\section{Table 3 All Funds: Comparison of AUM in High vs. Low Entry Load Funds}

This table presents regression results on the impact of the entry load ban on assets under management in high entry load funds versus low entry load funds. The dependent variable is the logarithm of assets under management in the fund. The data includes monthly observations over the period April 2006 through June 2012. The Post Reform dummy variable takes a value of one for the months August, 2009 and afterwards, and zero otherwise. The High Entry Load Fund variable takes a value of one for funds that charged an entry load of 2.25 percent or higher in the pre-reform period. Post*High Entry Load Fund is an interaction the Post Reform variable and the High Entry Load Fund variable. The variable Lag Ranked Returns Low is defined as min(.5, Rank), where Rank is defined as the percentile ranking $(0$ - 100) of the fund's past six month returns within its category. The variable Lag Ranked Returns High is defined as Rank - Lag Ranked Returns Low. Family*Post Reform FE are a set of fixed effects for each fund family separately in the pre-reform period and the post-reform period.

\begin{tabular}{|c|c|c|c|c|c|}
\hline VARIABLES & $(1)$ & $(2)$ & $(3)$ & (4) & $(5)$ \\
\hline Post*High Entry Load Group & $\begin{array}{c}-0.27^{*} \\
(0.14)\end{array}$ & $\begin{array}{l}-0.063 \\
(0.096)\end{array}$ & $\begin{array}{c}-0.071 \\
(0.096)\end{array}$ & $\begin{array}{l}-0.018 \\
(0.092)\end{array}$ & $\begin{array}{c}0.054 \\
(0.093)\end{array}$ \\
\hline Post Reform & $\begin{array}{c}0.31^{* *} \\
(0.12)\end{array}$ & $\begin{array}{c}0.30^{* * *} \\
(0.090)\end{array}$ & & & \\
\hline High Entry Load Group & $\begin{array}{c}1.50^{* * *} \\
(0.19)\end{array}$ & & & & \\
\hline Lag Ranked Returns Low & & & & & $\begin{array}{l}-0.00050 \\
(0.00054)\end{array}$ \\
\hline Lag Ranked Returns High & & & & & $\begin{array}{c}-0.0022^{* * *} \\
(0.00058)\end{array}$ \\
\hline Constant & $\begin{array}{c}4.70^{* * *} \\
(0.17)\end{array}$ & $\begin{array}{c}5.74^{* * *} \\
(0.017)\end{array}$ & $\begin{array}{c}5.54^{* * *} \\
(0.059)\end{array}$ & $\begin{array}{c}5.62^{* * *} \\
(0.052)\end{array}$ & $\begin{array}{c}4.98^{* * *} \\
(0.15)\end{array}$ \\
\hline Observations & 46771 & 46771 & 46771 & 46771 & 41837 \\
\hline R-squared & 0.061 & 0.926 & 0.929 & 0.936 & 0.943 \\
\hline Fund FE & NO & YES & YES & YES & YES \\
\hline Month*Year FE & $\mathrm{NO}$ & $\mathrm{NO}$ & YES & YES & YES \\
\hline Family*Post Reform FE & $\mathrm{NO}$ & $\mathrm{NO}$ & NO & YES & YES \\
\hline Mean Log AUM & 5.87 & 5.87 & 5.87 & 5.87 & 5.94 \\
\hline S.D. $\log (A U M)$ & 2.42 & 2.42 & 2.42 & 2.42 & 2.38 \\
\hline
\end{tabular}


Table 4 Excluding Income Funds: Comparison of AUM in High vs. Low Entry Load Funds

This table presents regression results on the impact of the entry load ban on assets under management in high entry load funds versus low entry load funds. The sample excludes income funds that only held a small proportion of assets in equity. The dependent variable is the logarithm of assets under management in the fund. The data includes monthly observations over the period April 2006 through June 2012. The Post Reform dummy variable takes a value of one for the months August, 2009 and afterwards, and zero otherwise. The High Entry Load Fund variable takes a value of one for funds that charged an entry load of 2.25 percent or higher in the pre-reform period. Post*High Entry Load Fund is an interaction the Post Reform variable and the High Entry Load Fund variable. The variable Lag Ranked Returns Low is defined as $\min (.5$, Rank), where Rank is defined as the percentile ranking (0 100) of the fund's past six month returns within its category. The variable Lag Ranked Returns High is defined as Rank - Lag Ranked Returns Low. Family*Post Reform FE are a set of fixed effects for each fund family separately in the pre-reform period and the post-reform period.

\begin{tabular}{lccccc}
\hline & $(1)$ & $(2)$ & $(3)$ & $(4)$ & $(5)$ \\
VARIABLES & & & & & \\
\hline & & & & & \\
Post*High Entry Load Fund & -0.075 & $0.17^{*}$ & $0.17^{*}$ & $0.27^{* *}$ & $0.36^{* * *}$ \\
& $(0.15)$ & $(0.10)$ & $(0.10)$ & $(0.11)$ & $(0.11)$ \\
Post Reform & 0.11 & 0.062 & & & \\
& $(0.14)$ & $(0.094)$ & & & \\
High Entry Load Fund & $1.33^{* * *}$ & & & & \\
& $(0.21)$ & & & & -0.00014 \\
Lag Ranked Returns Low & & & & & $(0.00053)$ \\
& & & & & $-0.0025^{* * *}$ \\
Lag Ranked Returns High & & & & & \\
& & & & & \\
Constant & $4.89^{* * *}$ & $5.87^{* * *}$ & $5.67^{* * *}$ & $5.74^{* * *}$ & $4.79^{* * *}$ \\
& $(0.18)$ & $(0.017)$ & $(0.061)$ & $(0.053)$ & $(0.17)$ \\
Observations & & & & & \\
R-squared & 43155 & 43155 & 43155 & 43155 & 38862 \\
Fund FE & 0.048 & 0.928 & 0.932 & 0.937 & 0.945 \\
Month*Year FE & NO & YES & YES & YES & YES \\
Family*Post Reform FE & NO & NO & YES & YES & YES \\
Mean Log AUM & NO NO & NO & YES & YES \\
S.D. Log(AUM) & 5.97 & 5.97 & 5.97 & 5.97 & 6.03 \\
& 2.37 & 2.37 & 2.37 & 2.37 & 2.34 \\
\hline
\end{tabular}


Table 5 All Funds: Comparison of Net Flows to High vs. Low Entry Load Funds

This table presents regression results on the impact of the entry load ban on net flows in to high entry load funds versus low entry load funds. The dependent variable is the monthly net-flow in to the fund. The sample is trimmed to exclude the top and bottom one percent of net-flows. The Post Reform dummy variable takes a value of one for the months August, 2009 and afterwards, and zero otherwise. The High Entry Load Fund variable takes a value of one for funds that charged an entry load of 2.25 percent or higher in the pre-reform period. Post*High Entry Load Fund is an interaction the Post Reform variable and the High Entry Load Fund variable. The $\log (\mathrm{AUM}(\mathrm{t}-1))$ variable is the one-month lagged value of the logarithm of assets under management. The variable Lag Ranked Returns Low is defined as $\min (.5$, Rank), where Rank is defined as the percentile ranking $(0-100)$ of the fund's past six month returns within its category. The variable Lag Ranked Returns High is defined as Rank - Lag Ranked Returns Low. Family*Post Reform FE are a set of fixed effects for each fund family separately in the pre-reform period and the post-reform period.

\begin{tabular}{|c|c|c|c|c|c|c|}
\hline VARIABLES & (1) & $(2)$ & (3) & (4) & $(5)$ & (6) \\
\hline Post*High Entry Load Fund & $\begin{array}{l}0.66^{*} \\
(0.37)\end{array}$ & $\begin{array}{c}0.61 \\
(0.40)\end{array}$ & $\begin{array}{c}0.51 \\
(0.42)\end{array}$ & $\begin{array}{c}0.49 \\
(0.42)\end{array}$ & $\begin{array}{c}1.09^{* *} \\
(0.44)\end{array}$ & $\begin{array}{c}0.67 \\
(0.44)\end{array}$ \\
\hline Post Reform & $\begin{array}{c}-1.23^{* * *} \\
(0.34)\end{array}$ & $\begin{array}{c}-1.45^{* * *} \\
(0.37)\end{array}$ & $\begin{array}{c}-1.05^{* * *} \\
(0.39)\end{array}$ & & & \\
\hline High Entry Load Fund & $\begin{array}{c}-0.029 \\
(0.26)\end{array}$ & & & & & \\
\hline $\log (\operatorname{AUM}(\mathrm{t}-1))$ & & & $\begin{array}{c}-1.23^{* * *} \\
(0.15)\end{array}$ & $\begin{array}{c}-1.37^{* * *} \\
(0.16)\end{array}$ & $\begin{array}{c}-1.57^{* * *} \\
(0.16)\end{array}$ & $\begin{array}{c}-1.36^{* * *} \\
(0.16)\end{array}$ \\
\hline Lag Ranked Returns Low & & & & & & $\begin{array}{l}-0.0017 \\
(0.0039)\end{array}$ \\
\hline Lag Ranked Returns High & & & & & & $\begin{array}{c}0.045^{* * *} \\
(0.0046)\end{array}$ \\
\hline Constant & $\begin{array}{l}0.41^{*} \\
(0.23)\end{array}$ & $\begin{array}{c}0.52^{* * *} \\
(0.074)\end{array}$ & $\begin{array}{c}7.62^{* * *} \\
(0.85)\end{array}$ & $\begin{array}{c}6.11^{* * *} \\
(1.03)\end{array}$ & $\begin{array}{c}7.47^{* * *} \\
(1.01)\end{array}$ & $\begin{array}{c}8.92^{* * *} \\
(1.85)\end{array}$ \\
\hline Observations & 45993 & 45993 & 45968 & 45968 & 45968 & 41235 \\
\hline R-squared & 0.003 & 0.108 & 0.119 & 0.249 & 0.261 & 0.280 \\
\hline Fund FE & NO & YES & YES & YES & YES & YES \\
\hline Month*Year FE & $\mathrm{NO}$ & $\mathrm{NO}$ & NO & YES & YES & YES \\
\hline Family*Post Reform FE & $\mathrm{NO}$ & NO & NO & NO & YES & YES \\
\hline Mean Net Flow & 0.0023 & 0.0023 & 0.0032 & 0.0032 & 0.0032 & -0.037 \\
\hline S.D. Net Flow & 7.43 & 7.43 & 7.44 & 7.44 & 7.44 & 7.19 \\
\hline
\end{tabular}


Table 6 Excluding Income Funds: Comparison of Net Flows to High vs. Low Entry Load Funds

This table presents regression results on the impact of the entry load ban on net flows in to high entry load funds versus low entry load funds. The sample excludes income funds that only held a small proportion of assets in equity. The dependent variable is the monthly net-flow in to the fund. The sample is trimmed to exclude the top and bottom one percent of net-flows. The Post Reform dummy variable takes a value of one for the months August, 2009 and afterwards, and zero otherwise. The High Entry Load Fund variable takes a value of one for funds that charged an entry load greater than or equal to 2.25 percent prior the reform. Post*High Entry Load Fund is an interaction the Post Reform variable and the high entry load fund variable. The $\log (\mathrm{AUM}(\mathrm{t}-1))$ variable is the one-month lagged value of the logarithm of assets under management. The variable Lag Ranked Returns Low is defined as $\min (.5$, Rank), where Rank is defined as the percentile ranking (0 - 100) of the fund's past six month returns within its category. The variable Lag Ranked Returns High is defined as Rank - Lag Ranked Returns Low. Family*Post Reform FE are a set of fixed effects for each fund family separately in the pre-reform period and the post-reform period.

\begin{tabular}{lcccccc}
\hline & $(1)$ & $(2)$ & $(3)$ & $(4)$ & $(5)$ & $(6)$ \\
VARIABLES & & & & & & \\
\hline & & & & & & \\
Post*High Entry Load Fund & $1.36^{* * *}$ & $1.44^{* * *}$ & $1.62^{* * *}$ & $1.61^{* * *}$ & $2.57^{* * *}$ & $2.01^{* * *}$ \\
& $(0.46)$ & $(0.48)$ & $(0.49)$ & $(0.49)$ & $(0.54)$ & $(0.54)$ \\
Post Reform & $-1.96^{* * *}$ & $-2.30^{* * *}$ & $-2.18^{* * *}$ & & & \\
High Entry Load Fund & $(0.43)$ & $(0.46)$ & $(0.47)$ & & & \\
& -0.34 & & & & & \\
Log(AUM(t-1)) & $(0.33)$ & & & & & \\
& & & $-1.23^{* * *}$ & $-1.40^{* * *}$ & $-1.52^{* * *}$ & $-1.28^{* * *}$ \\
Lag Ranked Returns Low & & & $(0.15)$ & $(0.17)$ & $(0.17)$ & $(0.18)$ \\
& & & & & & -0.0025 \\
Lag Ranked Returns High & & & & & & $0.0037)$ \\
& & & & & & $0.0041^{* * *}$ \\
Constant & $0.73^{* *}$ & $0.60^{* * *}$ & $7.85^{* * *}$ & $5.96^{* * *}$ & $6.93^{* * *}$ & $7.17^{* * *}$ \\
& $(0.31)$ & $(0.078)$ & $(0.89)$ & $(1.06)$ & $(1.07)$ & $(1.85)$ \\
Observations & & & & & & \\
R-squared & 42461 & 42461 & 42444 & 42444 & 42444 & 38319 \\
Fund FE & 0.005 & 0.117 & 0.128 & 0.274 & 0.286 & 0.304 \\
Month*Year FE & NO & YES & YES & YES & YES & YES \\
Family*Post Reform FE & NO & NO & NO & YES & YES & YES \\
Mean Net Flow & NO & NO & NO & NO & YES & YES \\
S.D. Net Flow & -0.00043 & -0.00043 & -0.000089 & -0.000089 & -0.000089 & -0.025 \\
\hline
\end{tabular}




\section{Table 7 Index Funds: Comparison of AUM in High vs. Low Entry Load Funds}

This table presents regression results on the impact of the entry load ban on assets under management in high entry load index funds versus low entry load index funds were assets under management data were available continuously for the two year window around the policy change. The dependent variable is the logarithm of assets under management in the fund. The data includes monthly observations over the period April 2006 through June 2012. The Post Reform dummy variable takes a value of one for the months August, 2009 and afterwards, and zero otherwise. The High Entry Load Fund variable takes a value of one for funds that charged greater than a zero entry load in the pre-reform period. Post*High Entry Load Fund is an interaction the Post Reform variable and the High Entry Load Fund variable. The variable Lag Ranked Returns Low is defined as min(.5, Rank), where Rank is defined as the percentile ranking $(0-100)$ of the fund's past six month returns within its category. The variable Lag Ranked Returns High is defined as Rank - Lag Ranked Returns Low.

\begin{tabular}{lcccc}
\hline & $(1)$ & $(2)$ & $(3)$ & $(4)$ \\
VARIABLES & & & & \\
\hline & & & & \\
Post*High Entry Load Fund & 0.65 & -0.0088 & 0.0064 & 0.053 \\
& $(0.50)$ & $(0.47)$ & $(0.48)$ & $(0.46)$ \\
Post Reform & -0.27 & 0.27 & & \\
& $(0.46)$ & $(0.45)$ & & \\
High Entry Load Fund & $-1.88^{* * *}$ & & & \\
& $(0.42)$ & & & $-0.0062^{*}$ \\
Lag Ranked Returns Low & & & & $(0.0033)$ \\
& & & & -0.0029 \\
Lag Ranked Returns High & & & & $(0.0030)$ \\
Constant & & & & \\
& $5.75^{* * *}$ & $4.65^{* * *}$ & $4.15^{* * *}$ & $5.18^{* * *}$ \\
& $(0.34)$ & $(0.095)$ & $(0.29)$ & $(0.36)$ \\
Observations & & & & \\
R-squared & 2377 & 2377 & 2377 & 2121 \\
Fund FE & 0.195 & 0.842 & 0.852 & 0.862 \\
Month*Year FE & NO & YES & YES & YES \\
Mean Log AUM & NO & NO & YES & YES \\
S.D. Log(AUM) & 4.78 & 4.78 & 4.78 & 4.87 \\
& 1.91 & 1.91 & 1.91 & 1.83 \\
\hline
\end{tabular}


Table 8 Index Funds Balanced Sample: Comparison of AUM in High vs. Low Entry Load Funds

This table presents regression results on the impact of the entry load ban on assets under management in high entry load index funds versus low entry load index funds were assets under management data were available continuously for the two year window around the policy change. The dependent variable is the logarithm of assets under management in the fund. The data includes monthly observations over the period April 2006 through June 2012. The Post Reform dummy variable takes a value of one for the months August, 2009 and afterwards, and zero otherwise. The High Entry Load Fund variable takes a value of one for funds that charged greater than a zero entry load in the pre-reform period. Post*High Entry Load Fund is an interaction the Post Reform variable and the High Entry Load Fund variable. The variable Lag Ranked Returns Low is defined as min(.5, Rank), where Rank is defined as the percentile ranking $(0-100)$ of the fund's past six month returns within its category. The variable Lag Ranked Returns High is defined as Rank - Lag Ranked Returns Low.

\begin{tabular}{lcccc}
\hline & $(1)$ & $(2)$ & $(3)$ & $(4)$ \\
VARIABLES & & & & \\
\hline & & & & \\
Post*High Entry Load Fund & 0.22 & -0.040 & -0.040 & -0.052 \\
& $(0.46)$ & $(0.35)$ & $(0.35)$ & $(0.35)$ \\
Post Reform & 0.0083 & 0.26 & & \\
& $(0.39)$ & $(0.31)$ & & \\
High Entry Load Fund & $-1.16^{* * *}$ & & & \\
& $(0.39)$ & & & 0.00031 \\
Lag Ranked Returns Low & & & & $(0.0046)$ \\
& & & & -0.0012 \\
Lag Ranked Returns High & & & & $(0.0047)$ \\
& $5.59^{* * *}$ & $4.96^{* * *}$ & $5.15^{* * *}$ & $5.18^{* * *}$ \\
Constant & $(0.31)$ & $(0.083)$ & $(0.16)$ & $(0.30)$ \\
& & & & \\
Observations & 788 & 788 & 788 & 758 \\
R-squared & 0.129 & 0.879 & 0.883 & 0.878 \\
Fund FE & NO & YES & YES & YES \\
Month*Year FE & NO & NO & YES & YES \\
Mean Log AUM & 5.09 & 5.09 & 5.09 & 5.14 \\
S.D. Log(AUM) & 1.51 & 1.51 & 1.51 & 1.51 \\
\hline
\end{tabular}




\section{Table 9 Index Funds: Comparison of Net Flows in High vs. Low Entry Load Funds}

This table presents regression results on the impact of the entry load ban on assets under management in high entry load index funds versus low entry load index funds were assets under management data were available continuously for the two year window around the policy change. The dependent variable is the logarithm of assets under management in the fund. The data includes monthly observations over the period April 2006 through June 2012. The Post Reform dummy variable takes a value of one for the months August, 2009 and afterwards, and zero otherwise. The High Entry Load Fund variable takes a value of one for funds that charged greater than a zero entry load in the pre-reform period. Post*High Entry Load Fund is an interaction the Post Reform variable and the High Entry Load Fund variable. The variable Lag Ranked Returns Low is defined as min(.5, Rank), where Rank is defined as the percentile ranking $(0-100)$ of the fund's past six month returns within its category. The variable Lag Ranked Returns High is defined as Rank - Lag Ranked Returns Low.

\begin{tabular}{|c|c|c|c|c|c|}
\hline VARIABLES & (1) & $(2)$ & (3) & (4) & $(5)$ \\
\hline Post*High Entry Load Fund & $\begin{array}{l}-0.80 \\
(0.92)\end{array}$ & $\begin{array}{l}-0.049 \\
(1.39)\end{array}$ & $\begin{array}{l}-0.24 \\
(1.19)\end{array}$ & $\begin{array}{l}-0.44 \\
(1.31)\end{array}$ & $\begin{array}{l}-1.20 \\
(1.26)\end{array}$ \\
\hline Post Reform & $\begin{array}{c}-2.05^{* *} \\
(0.81)\end{array}$ & $\begin{array}{c}-2.53^{* *} \\
(1.19)\end{array}$ & $\begin{array}{l}-1.57 \\
(1.00)\end{array}$ & & \\
\hline High Entry Load Fund & $\begin{array}{l}-0.62 \\
(0.95)\end{array}$ & & & & \\
\hline $\log (\operatorname{AUM}(\mathrm{t}-1))$ & & & $\begin{array}{c}-2.40^{* * *} \\
(0.37)\end{array}$ & $\begin{array}{c}-3.21^{* * *} \\
(0.48)\end{array}$ & $\begin{array}{c}-3.01^{* * *} \\
(0.45)\end{array}$ \\
\hline Lag Ranked Returns Low & & & & & $\begin{array}{c}0.031 \\
(0.019)\end{array}$ \\
\hline Lag Ranked Returns High & & & & & $\begin{array}{c}-0.0093 \\
(0.032)\end{array}$ \\
\hline Constant & $\begin{array}{c}3.01 * * * \\
(0.81)\end{array}$ & $\begin{array}{c}2.67^{* * *} \\
(0.32)\end{array}$ & $\begin{array}{c}13.6^{* * *} \\
(1.75)\end{array}$ & $\begin{array}{l}11.6^{* *} \\
(4.71)\end{array}$ & $\begin{array}{c}18.6^{* * *} \\
(2.71)\end{array}$ \\
\hline Observations & 2240 & 2240 & 2240 & 2240 & 2016 \\
\hline R-squared & 0.017 & 0.085 & 0.112 & 0.316 & 0.335 \\
\hline Fund FE & $\mathrm{NO}$ & YES & YES & YES & YES \\
\hline Month*Year FE & $\mathrm{NO}$ & $\mathrm{NO}$ & $\mathrm{NO}$ & YES & YES \\
\hline Mean Net Flow & 1.37 & 1.37 & 1.37 & 1.37 & 1.35 \\
\hline S.D. Net Flow & 10.5 & 10.5 & 10.5 & 10.5 & 10.3 \\
\hline
\end{tabular}




\section{Table 10 Index Funds Balanced Sample: Comparison of Net Flows in High vs. Low Entry Load Funds}

This table presents regression results on the impact of the entry load ban on assets under management in high entry load index funds versus low entry load index funds were assets under management data were available continuously for the two year window around the policy change. The dependent variable is the logarithm of assets under management in the fund. The data includes monthly observations over the period April 2006 through June 2012. The Post Reform dummy variable takes a value of one for the months August, 2009 and afterwards, and zero otherwise. The High Entry Load Fund variable takes a value of one for funds that charged greater than a zero entry load in the pre-reform period. Post*High Entry Load Fund is an interaction the Post Reform variable and the High Entry Load Fund variable. The variable Lag Ranked Returns Low is defined as min(.5, Rank), where Rank is defined as the percentile ranking $(0-100)$ of the fund's past six month returns within its category. The variable Lag Ranked Returns High is defined as Rank - Lag Ranked Returns Low.

\begin{tabular}{|c|c|c|c|c|c|}
\hline VARIABLES & (1) & (2) & (3) & (4) & (5) \\
\hline Post*High Entry Load Fund & $\begin{array}{c}1.33 \\
(0.79)\end{array}$ & $\begin{array}{l}-0.27 \\
(1.52)\end{array}$ & $\begin{array}{c}0.25 \\
(1.17)\end{array}$ & $\begin{array}{c}0.64 \\
(1.36)\end{array}$ & $\begin{array}{c}0.64 \\
(1.38)\end{array}$ \\
\hline Post Reform & $\begin{array}{c}-3.22^{* * *} \\
(0.96)\end{array}$ & $\begin{array}{l}-2.22 \\
(1.40)\end{array}$ & $\begin{array}{l}0.087 \\
(1.29)\end{array}$ & & \\
\hline High Entry Load Fund & $\begin{array}{l}-1.15 \\
(0.78)\end{array}$ & & & & \\
\hline $\log (\operatorname{AUM}(\mathrm{t}-1))$ & & & $\begin{array}{c}-6.64^{* * *} \\
(1.77)\end{array}$ & $\begin{array}{c}-11.6^{* * *} \\
(1.48)\end{array}$ & $\begin{array}{c}-11.9^{* * *} \\
(1.81)\end{array}$ \\
\hline Lag Ranked Returns Low & & & & & $\begin{array}{c}-0.024 \\
(0.040)\end{array}$ \\
\hline Lag Ranked Returns High & & & & & $\begin{array}{c}0.039 \\
(0.054)\end{array}$ \\
\hline Constant & $\begin{array}{c}1.61^{* *} \\
(0.69)\end{array}$ & $\begin{array}{c}1.17^{* * *} \\
(0.36)\end{array}$ & $\begin{array}{c}35.0^{* * *} \\
(9.15)\end{array}$ & $\begin{array}{c}57.5^{* * *} \\
(8.19)\end{array}$ & $\begin{array}{c}59.9 * * * \\
(10.7)\end{array}$ \\
\hline Observations & 400 & 400 & 400 & 400 & 396 \\
\hline R-squared & 0.028 & 0.053 & 0.076 & 0.482 & 0.482 \\
\hline Fund FE & NO & YES & YES & YES & YES \\
\hline Month*Year FE & $\mathrm{NO}$ & $\mathrm{NO}$ & $\mathrm{NO}$ & YES & YES \\
\hline Mean Net Flow & -0.17 & -0.17 & -0.17 & -0.17 & -0.16 \\
\hline S.D. Net Flow & 7.84 & 7.84 & 7.84 & 7.84 & 7.87 \\
\hline
\end{tabular}




\section{Data Appendix}

\subsection{Terms Used to Identify Funds Dropped from Sample}

Any fund with one of the following terms was eliminated from the sample to ensure the sample was primarily composed of equity funds that retail investors might plausibly invest in:

fixed, institutional, liquid, gilt, treasury, series, income, dividend, fmp, debt, bond, instn, g-sec, floating, money market, quarterly interval, floater, ultra short term, sundaram money fund, rlexible fund, ftp, micf, mgst, mglt, credit opportunities, floating rate, short term plan, money manager, government securities, deposit fund, cash management, mmis, savings plus, govt securities, triple ace, short term fund, quarterly plan, saving advantage, savings advantage, ssif, providend fund, gsf, cash fund, cf-plan, ust growth, very cautious, sweep, regular savings, medium term plan, long term plan, monthly interval, half yearly interval, annual interval, hsbc interval, hdfc short term opportunities, hdfc multiple yield, hdfc high interest, gssif, gfrf, overnight, money plus, fortis interval, short maturity, insta cash, cash opportunities, life govt, cash manager 


\section{Figure 17 Entry Loads on High Vs. Low Fee Index Funds}

This figure shows the average entry loads charged by funds in the high entry load index fund group and the low entry load index fund group. The high entry load group is defined as any index fund that charged an entry load greater than zero prior to the reform; the low entry load group is the set of index funds that charged zero entry loads prior to the reform. The left-axis is the scale for high entry load funds, and the right axis is the scale for low entry load funds. The dashed vertical line indicates the date the policy went in to force (August 2009).

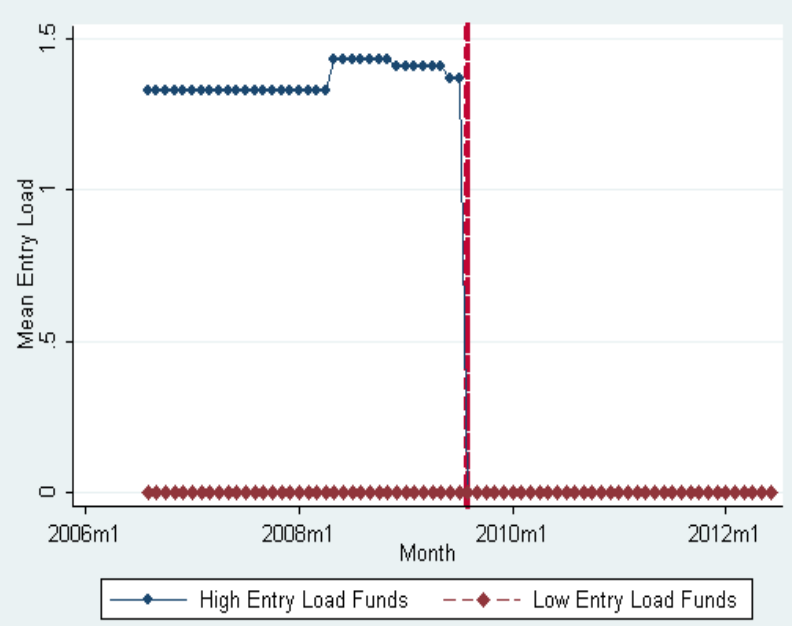

\section{Figure 18 Returns on High Vs. Low Fee Index Funds}

The right figure shows the average returns earned by funds in the high and low index fund groups. The left and right y-axis scales refer to the mean returns in to the high and low entry load groups respectively. The high entry load group is defined as any index fund that charged an entry load greater than zero prior to the reform; the low entry load group is the set of index funds that charged zero entry loads prior to the reform. The left-axis is the scale for high entry load funds, and the right axis is the scale for low entry load funds. The dashed vertical line indicates the date the policy went in to force (August 2009).

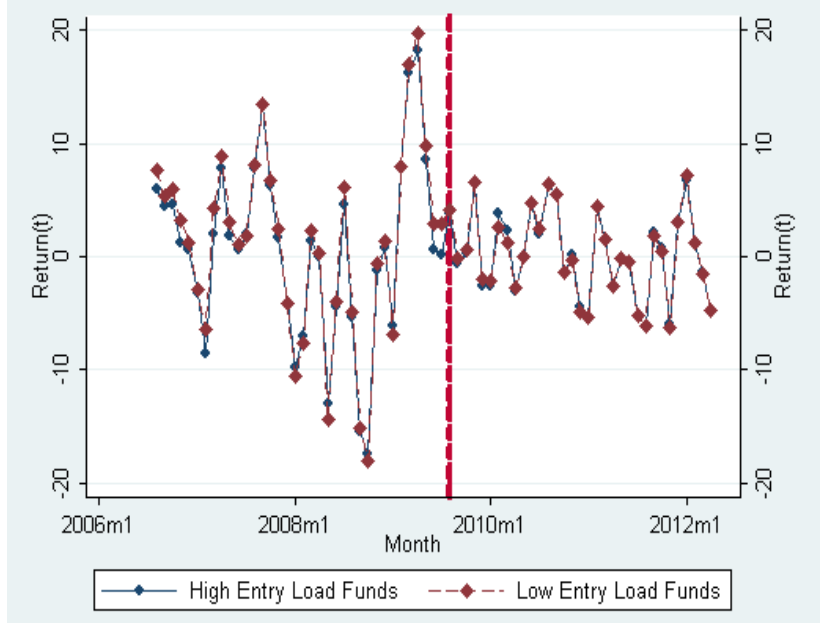

